\title{
Article
}

\section{Synthesis of Highly-Dispersed Graphene Oxide Nanoribbons-Functionalized Carbon Nanotubes-Graphene Oxide (GNFG) Complex and Its Application in Enhancing the Mechanical Properties of Cementitious Composites}

\author{
Peiqi Li ${ }^{1}$, Junxing Liu ${ }^{1} \mathbb{D}$, Sungwun Her ${ }^{1}$, Erfan Zal Nezhad ${ }^{2}$, Seungmin Lim ${ }^{3}$ and Sungchul Bae ${ }^{1, *(\mathbb{C}}$ \\ 1 Department of Architectural Engineering, Hanyang University, Seoul 04763, Korea; \\ lipeiqi1995@hanyang.ac.kr (P.L.); liujx128119@hanyang.ac.kr (J.L.); sung0@hanyang.ac.kr (S.H.) \\ 2 Department of Biomedical Engineering, University of Texas, San Antonio, TX 78249, USA; \\ erfan.zalnezhad@utsa.edu \\ 3 Department of Architecture, Kangwon National University, Chuncheon 24341, Korea; smlim@kangwon.ac.kr \\ * Correspondence: sbae@hanyang.ac.kr
}

Citation: Li, P.; Liu, J.; Her, S.; Zal Nezhad, E.; Lim, S.; Bae, S. Synthesis of Highly-Dispersed Graphene Oxide Nanoribbons-Functionalized Carbon Nanotubes-Graphene Oxide (GNFG) Complex and Its Application in

Enhancing the Mechanical Properties of Cementitious Composites.

Nanomaterials 2021, 11, 1669. https:// doi.org/10.3390/nano11071669

Academic Editors: Edgar ORear and Fernando Esteban Florez

Received: 2 June 2021

Accepted: 23 June 2021

Published: 25 June 2021

Publisher's Note: MDPI stays neutral with regard to jurisdictional claims in published maps and institutional affiliations.

\begin{abstract}
In this study, a graphene oxide nanoribbons-functionalized carbon nanotubes-graphene oxide (GNFG) complex was hydrothermally synthesized as a nanomaterial for reinforcing cementitious composites, using a modified Hummers' method. Three types of components existed in the GNFG: Type I, the functionalized carbon nanotubes-graphene oxide nanoribbons (FCNTs-GNR); and types II and III are graphene oxide (GO) and functionalized carbon nanotubes (FCNTs), respectively, which exist independently. The dispersivity of GNFG and its effects on the mechanical properties, hydration process, and microstructures of cement pastes were evaluated, and the results were compared with those using cement pastes incorporating other typical carbon nanomaterials. The results demonstrated that dispersion of GNFG in aqueous solutions was superior to that of the CNTs, FCNTs, and GO/FCNTs mixture. Furthermore, the highly-dispersed GNFG (0.05 wt.\%) improved the mechanical properties of the cement paste after 28 days of hydration and promoted the hydration of cement compared to CNTs, GO, and GO/FCNTs mixture (0.05 wt.\%). The results in this study validated the feasibility of using GNFG with enhanced dispersion as a new nano-reinforcing agent for various cementitious systems.
\end{abstract}

Keywords: graphene oxide nanoribbons; graphene oxide; functionalized carbon nanotubes; cement paste; mechanical properties

\section{Introduction}

Since the development of Portland cement in 1824, it has gradually become the most extensively used building material worldwide due to its excellent performance and low cost [1]. Portland cement is usually applied as a binder to form cementitious materials, including concrete, along with other aggregates (sand and gravel). However, owing to the brittleness and lack of flexural/tensile strength of cementitious materials, many studies have focused on improving its mechanical strength. The typical method for improving the flexural/tensile strength of cementitious materials is to employ fibers such as polypropylene fiber, carbon fiber, steel fiber, and glass fiber as reinforcing agents [2-6]. Xue et al. [7] and Cao et al. [8] reported that the fiber exhibited various reinforcement effects on cementitious materials due to their different types and lengths. Although these fibers can improve the tensile strength and toughness of cementitious materials, delaying the transformation of microcracks into microforms, they cannot constrain the development of microcracks [9]. Nanomaterials, such as nano-silica, nano-titanium dioxide $\left(\mathrm{TiO}_{2}\right)$, carbon nanotubes (CNTs), and graphene oxide (GO), have also been found to improve the mechanical properties of cementitious materials and hinder the spread of microcracks [10]. 
Among these materials, carbon nanomaterials, represented by CNTs and GO, are favored owing to their excellent mechanical properties $[11,12]$.

CNTs, developed by Iijima in 1991 [13], are an allotropic form of carbon with unique characteristics that make them suitable reinforcing agents in various fields [14]. The carbon atoms of the tubes are $\mathrm{sp}^{2}$ hybridized and combine through carbon-carbon bonds ( $\sigma$ bond) to form a hexagonal honeycomb structure [15]. This structure provides the unique mechanical properties of CNTs. The tensile strength and Young's modulus of CNTs exceed $60 \mathrm{GPa}$ [16] and 1.2 TPa [17], respectively. Therefore, CNTs are considered to be an ideal nanomaterial and one of the most promising nanomaterials in the 21st century [18]. However, because of the strong van der Waals forces between the CNTs and the absence of hydrophilic functional groups on the surface, it is difficult to uniformly disperse CNTs in aqueous solutions. The precondition of using CNTs as a reinforcing material in cementbased materials is uniform dispersion. Three methods are currently used to disperse CNTs: ultrasonication treatment, use of surfactants, and functionalization of the CNTs [19-21]. $\mathrm{Xu}$ et al. [22] reported that CNTs could reduce the porosity of cement by filling the pores in the cement matrix, and found that the flexural strength of the cement paste increased by the addition of CNTs ( $0.05 \mathrm{wt} . \%)$ that sonication and surfactants were used.

In recent years, functionalized CNTs (FCNTs) have gradually attracted attention. The purpose of functionalizing the CNTs is to address the poor dispersion of pure CNTs [23]. CNTs can be functionalized using chemical (covalent) and physical (non-covalent) methods [24]. Generally, CNTs have several inherent structural defects. During chemical functionalization, oxygen-containing functional groups are inserted at these defect sites by damaging inherent defects using strong acids [25]. This method is easy to achieve in the laboratory; thus, in this study, we focus on the chemical method. Furthermore, Mousavi et al. [26] demonstrated that the ultrasonic treatment can increase the dispersion of FCNTs in aqueous solutions. When the FCNTs content was $0.05 \mathrm{wt} . \%$, the compressive and flexural strengths of cement paste increased by $26.6 \%$ and $3.2 \%$, respectively.

As a two-dimensional (2D) carbon nanomaterial, GO has also received widespread attention from researchers. It is a hydrophilic material with a variety of oxygen-containing functional groups (carboxyl and hydroxyl); thus, GO disperses better in aqueous solutions and is more uniformly distributed in the cement matrix than CNTs and FCNTs [27]. The 2D structure of GO confers excellent mechanical properties, which are superior to nano-fibrillar cellulose, nano calcium carbonate, and nano-clay [28]. Specifically, the elastic modulus and fracture toughness of GO are $32 \mathrm{GPa}$ and $120 \mathrm{MPa}$, respectively [29]. Peng et al. [30] demonstrated that GO can improve the microscopic morphology of cement hydration products, thereby increasing the strength of hardened cement paste. When the water-tocement ratio $(\mathrm{w} / \mathrm{c})$ was 0.35 , the incorporation of $0.03 \mathrm{wt} . \% \mathrm{GO}$ increased the flexural strength of the cement mortar by $21.86 \%$. Pan et al. [31] also reported that GO interacted strongly with the cement matrix due to the wrinkled surface structure that provided more nucleation sites for cement hydration, enhancing the mechanical properties of the cement paste. An et al. [32] reported similar results: the large specific surface area of GO enhanced the nucleation effect and promoted hydration. After 28 days of curing, cement paste containing $0.05 \mathrm{wt} . \% \mathrm{GO}$ exhibited increases in the compressive strength and flexural strength by $25.5 \%$ and $37.3 \%$, respectively.

As research on the enhancing effect of single carbon nanomaterial in cement-based materials has proceeded, the synergistic effect that may exist between multiple nanomaterials has entered the vision of researchers [33]. Many studies have demonstrated the enhancing effects of CNTs or GO on cementitious materials; however, only a few studies have demonstrated the co-effect of CNTs and GO on the mechanical properties of cement paste. Lu et al. [34] found that the electrostatic repulsion between CNTs and GO in a solution can overcome the van der Waals force between CNTs, thus improve the dispersion of CNTs. Moreover, when the $\mathrm{w} / \mathrm{c}$ ratio was 0.4 , the flexural and compressive strengths of the cement paste containing $0.025 \mathrm{wt} . \%$ CNTs and $0.025 \mathrm{wt} . \% \mathrm{GO}$ (total content of $0.05 \mathrm{wt} . \%$ ) were increased by $21.13 \%$ and $24.21 \%$, respectively. These increases were greater than those 
obtained from the addition of $0.05 \mathrm{wt}$ \% CNTs (flexural: $10.14 \%$, compressive: $6.40 \%$ ) or 0.05 wt. \% GO (flexural: $16.20 \%$, compressive: $11.05 \%$ ). Zhou et al. [35] also reported that $\mathrm{GO} / \mathrm{CNTs}$ could form a relatively stable dispersion system; because of the filling effect of GO/CNTs, the porosity was reduced and the mechanical strength of the cement paste increased. Furthermore, Kaury et al. [36] reported that the dispersion of FCNTs and GO was improved after mixing owing to the co-effect, and the strength of mortars can be significantly improved when using this mixture compared to adding either FCNTs or GO. Although this synergistic effect can appropriately improve the poor dispersion of CNTs, the results are still not satisfying.

Herein, as a new type of nano-reinforcing agent in cement-based materials, highly dispersed graphene oxide nanoribbons (GNR)-functionalized carbon nanotubes (FCNTs)graphene oxide (GO), GNFG complex was synthesized, which has good dispersion and also improves the mechanical properties of cementitious materials. The structure, functional groups, and dispersibility of GNFG were investigated and compared to those of CNTs, FCNTs, GO, and GO/FCNTs mixture. The morphologies and chemical bonds of the nanomaterials were characterized by transmission electron microscopy (TEM) and Fourier transform infrared spectroscopy (FTIR), respectively. X-ray diffraction (XRD) was employed to characterize the crystal structure of the nanomaterials and to qualitatively analyze the cement hydration products. The dispersion of these nanomaterials was tested by ultraviolet-visible (UV-vis) spectroscopy. To confirm the effect of GNFG in the cementbased materials, the hydration products, microstructure, and hydration kinetics of the cement paste with GNFG were investigated via thermogravimetric (TG) and differential thermogravimetric (DTG) analysis, scanning electron microscopy (SEM), and isothermal conduction calorimetry, respectively.

\section{Experimental Procedure}

\subsection{Materials}

Ordinary Portland cement (OPC) CEM I 42.5R provided by Sungshin Co. Ltd. (Seoul, Korea) was used as the binder material to prepare the cement paste. Multiwalled CNTs were purchased from Hengqiu Technology (Suzhou, China). Graphite flake powders were procured from Alfa Aesar (Haverhill, MA, USA). The chemical composition of OPC and the physical properties of the CNTs and graphite are shown in Tables 1-3, respectively. To disperse the nanomaterials in the cement matrix, a polycarboxylate superplasticizer (SP, ExCon SP20, Buildex Co., Ltd., Cheonan-si, Chungcheongnam-do, Korea.) was used, and its properties are listed in Table 4.

Table 1. Chemical composition of OPC.

\begin{tabular}{ccccccccccc}
\hline $\begin{array}{c}\text { Chemical } \\
\text { Composition }\end{array}$ & $\mathrm{SiO}_{2}$ & $\mathrm{Al}_{2} \mathrm{O}_{3}$ & $\mathrm{Fe}_{2} \mathrm{O}_{3}$ & $\mathrm{CaO}$ & $\mathrm{MgO}$ & $\mathrm{K}_{2} \mathrm{O}$ & $\mathrm{SO}_{3}$ & $\mathrm{TiO}_{2}$ & $\mathrm{LOI}$ & Total \\
\hline (wt.\%) & 18.43 & 2.83 & 2.17 & 68.17 & 2.37 & 1.11 & 3.03 & 0.15 & 1.72 & 100 \\
\hline
\end{tabular}

Table 2. Properties of the CNTs.

\begin{tabular}{ccccccc}
\hline $\begin{array}{c}\text { Outside } \\
\text { Diameter }(\mathbf{n m})\end{array}$ & $\begin{array}{c}\text { Inside Dimeter } \\
(\mathbf{n m})\end{array}$ & $\begin{array}{c}\text { Length } \\
(\boldsymbol{\mu m})\end{array}$ & $\begin{array}{c}\text { Ash } \\
\mathbf{( \% )}\end{array}$ & $\begin{array}{c}\text { Purity } \\
(\mathbf{\%})\end{array}$ & $\begin{array}{c}\text { SSA } \\
\left(\mathbf{m}^{2} / \mathbf{g}\right)\end{array}$ & Color \\
\hline $10-20$ & $5-10$ & $10-30$ & $<1.5$ & 95 & $>200$ & Black \\
\hline SSA: specific surface area. & & & & & &
\end{tabular}

Table 3. Properties of graphite flakes.

\begin{tabular}{cccccc}
\hline Mesh & $\begin{array}{c}\text { Purity } \\
(\mathbf{\%})\end{array}$ & $\begin{array}{c}\text { Density } \\
(\mathrm{g} / \mathrm{mL})\end{array}$ & $\begin{array}{c}\text { Boiling Point } \\
\left({ }^{\circ} \mathbf{C}\right)\end{array}$ & $\begin{array}{c}\text { Particle Size } \\
(\mu \mathrm{m})\end{array}$ & Color \\
\hline 325 & 99 & 2.2 & 4830 & $<50$ & Black \\
\hline
\end{tabular}


Table 4. Properties of the polycarboxylate superplasticizer.

\begin{tabular}{|c|c|c|c|}
\hline Water Content (\%) & $\begin{array}{c}\mathrm{pH} \text { Value } \\
(10 \% \text { Solution })\end{array}$ & $\begin{array}{c}\text { Active Component } \\
(\%)\end{array}$ & $\begin{array}{c}\text { Bulk Density } \\
\left(\mathrm{kg} / \mathrm{m}^{3}\right)\end{array}$ \\
\hline$<3$ & $6.0-8.0$ & $>90$ & 450 \\
\hline
\end{tabular}

\subsection{Preparation of GNFG, GO, FCNTs, and GO/FCNTs Mixture}

\subsubsection{Synthesis of GNFG and GO}

In 1958, Hummers et al. described a method to synthesize GO using a mixture of sodium nitrate $\left(\mathrm{NaNO}_{3}\right)$, potassium permanganate $\left(\mathrm{KMnO}_{4}\right)$, and concentrated sulfuric acid $\left(\mathrm{H}_{2} \mathrm{SO}_{4}\right)$, which is also known as Hummers' method [37]. Although Hummers' method has been used widely to synthesize GO [38], it still suffers from several drawbacks, including the generation of toxic gases $\left(\mathrm{NO}_{2}\right.$ and $\left.\mathrm{N}_{2} \mathrm{O}_{4}\right)$, nitrate residues, and low yields [27]. The Hummers' method has been modified in the past 20 years to address these problems [39]. Currently, most researchers utilize modified Hummers' method to synthesize GO, wherein the proportions of the experimental materials and process are changed [40].

GNFG was also synthesized using the modified Hummers' method. First, a combined mass of $1 \mathrm{~g}$ of graphite and CNTs (mass ratio of graphite: $\mathrm{CNTs}=2: 1$ ) and $0.65 \mathrm{~g}$ of $\mathrm{NaNO}_{3}$ were added to a beaker and mixed. The beaker was kept in an ice-water bath below $5{ }^{\circ} \mathrm{C}$. Subsequently, $30 \mathrm{~mL}$ of $\mathrm{H}_{2} \mathrm{SO}_{4}(95 \%)$ was transferred to the beaker and the mixture was stirred. After 3 min of stirring, $\mathrm{KMnO}_{4}(3.9 \mathrm{~g})$ was gradually added to the beaker and the mixture was stirred with a magnetic stirrer for $2 \mathrm{~h}$. Then, the beaker was transferred to a water bath $\left(35^{\circ} \mathrm{C}\right)$ and kept in the water bath for $30 \mathrm{~min}$. Next, $50 \mathrm{~mL}$ of distilled water was added dropwise to the mixture and the mixture was stirred for $30 \mathrm{~min}$. The temperature of the water bath was increased to $98{ }^{\circ} \mathrm{C}$ and maintained for $20 \mathrm{~min}$. Finally, a $30 \% \mathrm{H}_{2} \mathrm{O}_{2}$ solution $(5 \mathrm{~mL})$ was added dropwise to terminate the oxidation reaction. The mixture was filtered, and the remaining metal ions were removed by adding a $10 \% \mathrm{HCl}$ aqueous solution dropwise. Then, the solution was washed thoroughly with distilled water until the $\mathrm{pH}$ was approximately 7 . Finally, the filtered solid was dissolved in distilled water, sonicated for $30 \mathrm{~min}$, filtered again, and dried. A similar procedure was followed to synthesize GO using $1 \mathrm{~g}$ of graphite powder as the raw material. The GNFG and GO powders were obtained by drying in an oven at $60^{\circ} \mathrm{C}$ for $24 \mathrm{~h}$. In the preliminary experiment, the GNFG with the different mass ratio of graphite to CNTs (1:1, 2:1, and 4:1) were synthesized and their dispersity in aqueous solutions tested, as presented in Figure 1. GNFG with a mass ratio of 2:1 (graphite: CNTs) exhibited the best dispersion in the aqueous solution. Therefore, we used the GNFG with graphite and CNTs mass ratio of 2:1 for all measurements in this study.

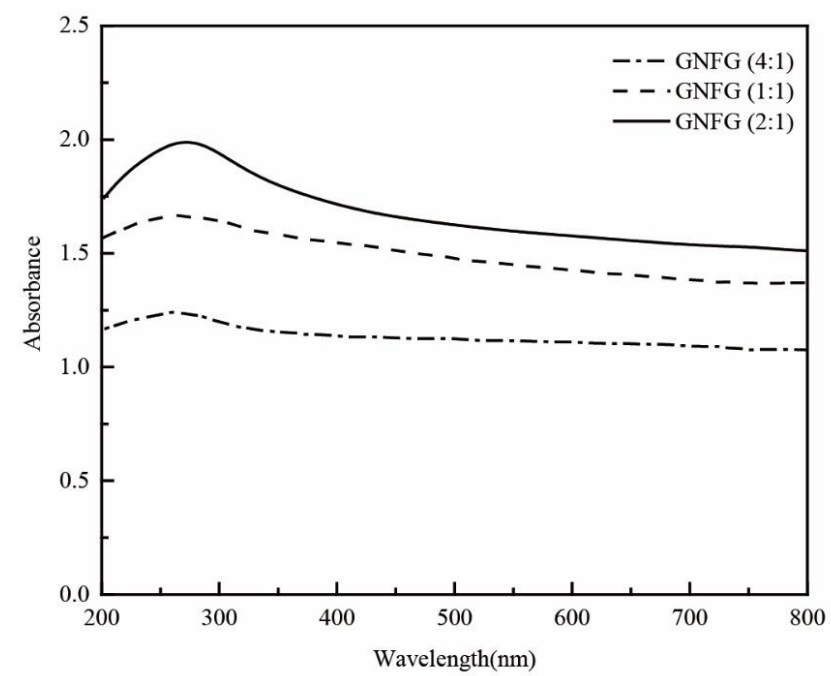

Figure 1. UV-vis spectra of GNFG synthesized using different ratios of graphite to CNTs. 


\subsubsection{Functionalization of the CNTs}

Many methods of functionalizing CNTs have been introduced in previous studies [41-43]. In our experiments, a relatively safe and simple method was chosen, as follows: $\mathrm{H}_{2} \mathrm{O}_{2}(50 \mathrm{~mL})$ was slowly added to $150 \mathrm{~mL}$ of $\mathrm{H}_{2} \mathrm{SO}_{4}(95 \%)$ to obtain a piranha solution; the mixture was left to cool and then used. Next, $0.3 \mathrm{~g}$ of CNTs were added to the piranha solution and the mixture was stirred for $30 \mathrm{~min}$. The mixed solution was then sonicated for $1 \mathrm{~h}$. After the ultrasonic treatment was completed, the solution was diluted with distilled water, filtered, and repeatedly washed to reach a $\mathrm{pH}$ of approximately 7 . Finally, The FCNTs powder was obtained by drying the filtered solid in an oven at $60{ }^{\circ} \mathrm{C}$ for $24 \mathrm{~h}$.

\subsubsection{Mixing of GO/FCNTs}

In order to compare with GNFG, the GO/FCNTs mixture was also prepared. We added $0.6 \mathrm{~g}$ of GO and $0.3 \mathrm{~g}$ of FCNTs (mass ratio of 2:1) to an aqueous solution and sonicated it for $15 \mathrm{~min}$ to ensure uniform mixing of GO and FCNTs. Then the mixture was filtered and the residue dried. Finally, a mixture of GO and FCNTs was obtained.

\subsection{Characterization of the GRAPHITE, GO, CNTs, FCNTs, GO/FCNTs Mixture, and GNFG}

The morphologies of graphite, GO, CNTs, FCNTs, GO/FCNTs mixture, and GNFG were determined using TEM (JEOL, JEM-2100F, Tokyo, Japan) with an electron source operating at an accelerating voltage of $220 \mathrm{kV}$. To prepare the samples, first, appropriate amounts of the graphite, GO, CNTs, FCNTs, GO/FCNTs mixture, and GNFG were dissolved in ethanol and ultrasonically dispersed for $15 \mathrm{~min}$ (Qsonica, Q700 Sonicator, Newtown, CT, USA, $20 \mathrm{kHz}$, Amplitude: 50\%) [34]. Next, the dispersions of graphite, GO, CNTs, FCNTs, GO/FCNTs mixture, and GNFG were placed on a holey carbon film on 400 mesh Cu grids. Finally, the $\mathrm{Cu}$ grids were dried in an oven at $65^{\circ} \mathrm{C}$ for $24 \mathrm{~h}$.

$\mathrm{XRD}$ analysis was performed to study the crystalline structure of the graphite, GO, CNTs, FCNTs, GO/FCNTs mixture, and GNFG using a Bruker D2 X-ray diffractometer $(\lambda=1.54 \AA)$ in the scattering $(2 \theta)$ range of $5-60^{\circ}$ with a step time of $1.5 \mathrm{~s}$ and step size of $0.01^{\circ}$. Phase identification was conducted using the DIFFRAC.EVA software. To evaluate the chemical bonds and functional groups of the graphite, GO, CNTs, FCNTs, GO/FCNTs mixture, and GNFG, FTIR was performed using a FTIR spectrometer (Spectrum Two FTIR spectrometer, PerkinElmer, Waltham, MA, USA) in the wavenumber range of 500 to $4000 \mathrm{~cm}^{-1}$.

A UV-vis absorption spectrophotometer (GENESYS 180, Thermo Fisher Scientific, Waltham, MA, USA) was used to measure the dispersion of the GO, CNTs, FCNTs, GO/FCNTs mixture, and GNFG in aqueous solutions. Before the test, $0.05 \mathrm{~g}$ of different nanomaterials were added to $30 \mathrm{~mL}$ of distilled water. The concentration of the test solution was the same as that of the solution added to the cement paste, i.e., $1.66 \mathrm{mg} / \mathrm{mL}$, followed by $15 \mathrm{~min}$ of sonication with a sonicator (Qsonica, Q700 Sonicator) at an amplitude of $50 \%$. As a rule, in the absorption UV-vis spectrum, the absorption is proportional to the concentration, according to the Beer-Lambert law [44]. However, only the low concentration of the solution obeys the Beer-Lambert Law [45]. Therefore, the solutions after ultrasound treatment were diluted to $0.1 \mathrm{mg} / \mathrm{mL}$ [46]. SP was not added to the solutions for this test to exclude the effect of SP on the dispersion of the nanomaterials.

An important aspect of this study is to investigate the role of highly dispersed GNFG in the enhancement of cement properties. Several previous studies have extensively compared the roles of GO, CNTs, FCNTs, and GO/FCNTs mixtures in enhancing the properties of cement [34,47-50]. However, the structure of FCNTs can be damaged by chemical treatment resulting in shorter lengths, smaller diameters, and rough surfaces. Therefore, the mechanical properties of pure CNTs are better than those of FCNTs [51]. Based on the above, in this study, the GO, CNTs, and GO/FCNTs mixture were compared with GNFG. 


\subsection{Preparation of the GO, CNTs, GO/FCNTs Mixture, and GNFG Cement Pastes}

Cement paste containing $0.025 \mathrm{wt} . \% \mathrm{CNTs} / 0.025 \mathrm{wt} . \% \mathrm{GO}$ composites can significantly improve various properties of the cement paste [34]. Therefore, the ratio of nanomaterials selected for this study was also $0.05 \%$ of the weight of cement, and the $\mathrm{w} / \mathrm{c}$ ratio was 0.3. The solution used to prepare specimens was obtained by adding $0.05 \mathrm{~g}$ of GO, CNTs, GO/FCNTs mixture, and GNFG to $30 \mathrm{~g}$ of distilled water. This solution was treated with ultrasonic waves to uniformly disperse the nanomaterials in water. However, if the energy of ultrasonic waves is too low, the dispersion will be non-uniform. In contrast, if the energy of the ultrasound is too high, the structure of the material will be damaged [52]. Hence, to ensure the same experimental conditions, four different nanomaterials were sonicated (Qsonica, Q700 Sonicator) using the same processing time and amplitude, which were $15 \mathrm{~min}$ and $50 \%$, respectively. In addition, the beaker with the solution was placed in an ice-water bath during the sonication process to prevent the solution temperature from increasing during continuous sonication. Five specimens were prepared as shown in Table 5. For each specimen, SP was added at a $0.1 \mathrm{wt} . \%$ dosage based on the cement weight.

Table 5. Mix proportions.

\begin{tabular}{cccccccc}
\hline Specimen & Cement (g) & Water (g) & SP (g) & GO (g) & CNTs (g) & GO/FCNTs (g) & GNFG (g) \\
\hline OPC & 100 & 30 & 0.1 & - & - & - & - \\
0.05 wt. $\%$ GO & 100 & 30 & 0.1 & 0.05 & - & - & - \\
0.05 wt. $\%$ CNTs & 100 & 30 & 0.1 & - & 0.05 & - & - \\
0.05 wt. $\%$ & 100 & 30 & 0.1 & - & - & 0.05 & - \\
GO/FCNTs & 100 & 30 & 0.1 & - & - & - & 0.05 \\
0.05 wt. $\%$ GNFG & 100 & & & & \\
\hline
\end{tabular}

Usually, SP is added to cement paste for two reasons. Firstly, SP is added to improve the workability of the cement paste, since the $\mathrm{w} / \mathrm{c}$ ratio was chosen to be small and the addition of nanomaterials will cause the workability of the cement paste to deteriorate $[53,54]$. Secondly, SP is used as a surfactant to disperse the nanomaterials in the cement matrix [53]. Although these nanomaterials can be relatively stable dispersed in aqueous solutions after sonication, previous studies have shown that, in the alkaline environment of the cement matrix, the dispersion of CNTs and GO will be reduced, causing agglomeration $[55,56]$. S. Chuah [55] reported that premixing SP with cement reduces the alkalinity of the cement matrix in the early stages of cement hydration, as well as reducing the effects of alkaline conditions on dispersion. Thus, in this work, cement $(100 \mathrm{~g})$ and $0.1 \mathrm{~g}$ SP were pre-mixed to obtain a uniform mixture. Then the GO, CNTs, GO/FCNTs mixture, and GNFG solutions were mixed with the cement and SP mixture using a paste mixer (Malcom, SPS-1, Tokyo, Japan) for $10 \mathrm{~min}$, respectively. Subsequently, the fresh cement paste was placed into compressive strength molds $\left(5 \times 5 \times 10 \mathrm{~mm}^{3}\right)$ and splitting tensile strength molds $\left(\Phi 10 \times 20 \mathrm{~mm}^{2}\right)$ and cured for $24 \mathrm{~h}$. After $24 \mathrm{~h}$, the specimens were demolded and stored in a constant temperature-humidity curing cabinet; the curing temperature and humidity were $25^{\circ} \mathrm{C}$ and $65 \%$, respectively.

\subsection{Compressive and Splitting Tensile Strength Tests}

To observe the variation of the mechanical properties of the cement paste with hydration time, the compressive and splitting tensile strength of the specimens were tested after curing $1,3,7$, and 28 days, respectively [57]. The compressive and splitting tensile strengths of the hydrated cement paste were measured using a micro-compressive machine (Deben, Micro-Compressive Machine, Edmunds, Suffolk, UK) [58]. Figure 2 shows a schematic of the compressive and splitting tensile strength tests $[57,59]$. The sizes of the samples used for the compressive and splitting tensile strength tests were $5 \times 5 \times 10 \mathrm{~mm}^{3}$ and $\Phi 10 \times 20 \mathrm{~mm}^{2}$, respectively. 
(a)

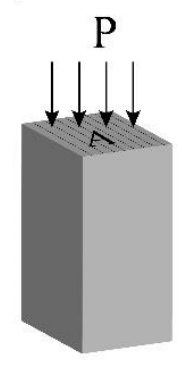

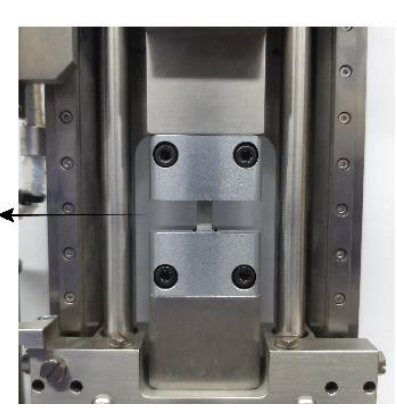

(b)
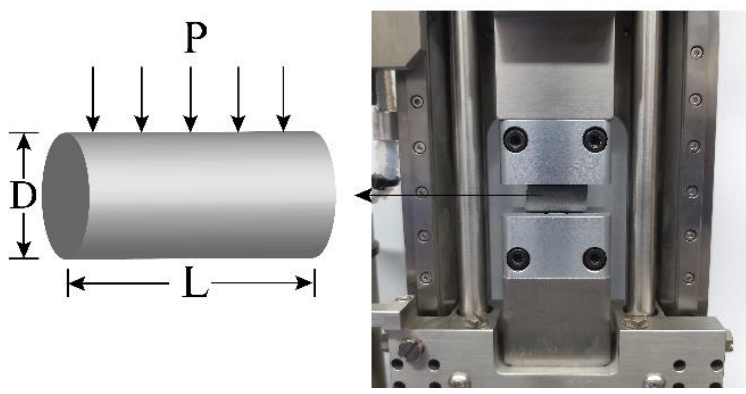

Figure 2. Schematics of strength tests: (a) compressive strength and (b) splitting tensile strength. Where: $(\mathbf{a}) \mathrm{F}=\mathrm{P} / \mathrm{A}$, (b) $\mathrm{T}=2 \mathrm{P} / \pi \mathrm{LD}$; F: Compressive strength (MPa); $\mathrm{T}$ : Splitting tensile strength (MPa); P: Maximum load applied to the specimen $(\mathrm{N})$; A: Cross-sectional area of the specimen $\left(\mathrm{mm}^{2}\right)$; L: Length of specimen $(\mathrm{mm})$; D: Diameter of specimen (mm).

\subsection{Microstructure and Mineral Analysis}

The microstructures of the fracture surfaces of the specimens after curing for 28 days were analyzed by SEM (Thermo Fisher Scientific, Verios G4, Waltham, MA, USA). XRD (Bruker, D2 PHASER, Billerica, MA, USA) and TG analysis (HITACHI, STA7200 Simultaneous Thermogravimetric Analyzer, Tokyo, Japan) were used to study the cement hydration products after curing for $1,3,7$, and 28 days. The TG experiments were conducted in a temperature range of 20 to $1000{ }^{\circ} \mathrm{C}$ with a heating rate of $10{ }^{\circ} \mathrm{C} / \mathrm{min}$, under an $\mathrm{N}_{2}$ atmosphere with a flow rate of $200 \mathrm{~mL} / \mathrm{min}$.

\subsection{Heat of Hydration}

Isothermal conduction calorimetry (TA instrument, TAM-air, New Castle, DE, USA) was conducted to evaluate the effects of GO, CNTs, GO/FCNTs mixture, and GNFG on the hydration process of the cement paste at an early stage (72 $\mathrm{h}$ ) [60]. According to the $\mathrm{w} / \mathrm{c}$ ratio, the cement, nanomaterials, SP, and water were mixed to a total mass of $5 \mathrm{~g}$. The aqueous solution containing the nanomaterials was sonicated before mixing with the cement.

\section{Results and Discussion}

\subsection{Characterization of the Graphite, GO, CNTs, FCNTs, GO/FCNTs Mixture, and GNFG 3.1.1. Morphology Investigation}

The TEM images of the graphite, GO, CNTs, FCNTs, GO/FCNTs mixture, and synthesized GNFG are shown in Figures 3 and 4. As shown in Figure 3a, CNTs with high aspect ratios are agglomerated due to severe entanglement of CNTs and the absence of hydrophilic functional groups in the structure, which reduced their dispersion in aqueous solutions [61]. Figure 3b shows the FCNTs morphology; the FCNTs are fractured at the ends and do not have closed caps. This is due to the oxidation of the CNTs [62]. Meanwhile, the degree of agglomeration of FCNTs remains relatively high [63]. Figure $3 c$ shows the morphological characteristics of graphite, indicating a multilayer graphite structure with a darker color. Figure $3 \mathrm{~d}$ shows that the surface morphology of GO is wrinkled, like crumpled paper [64]. 


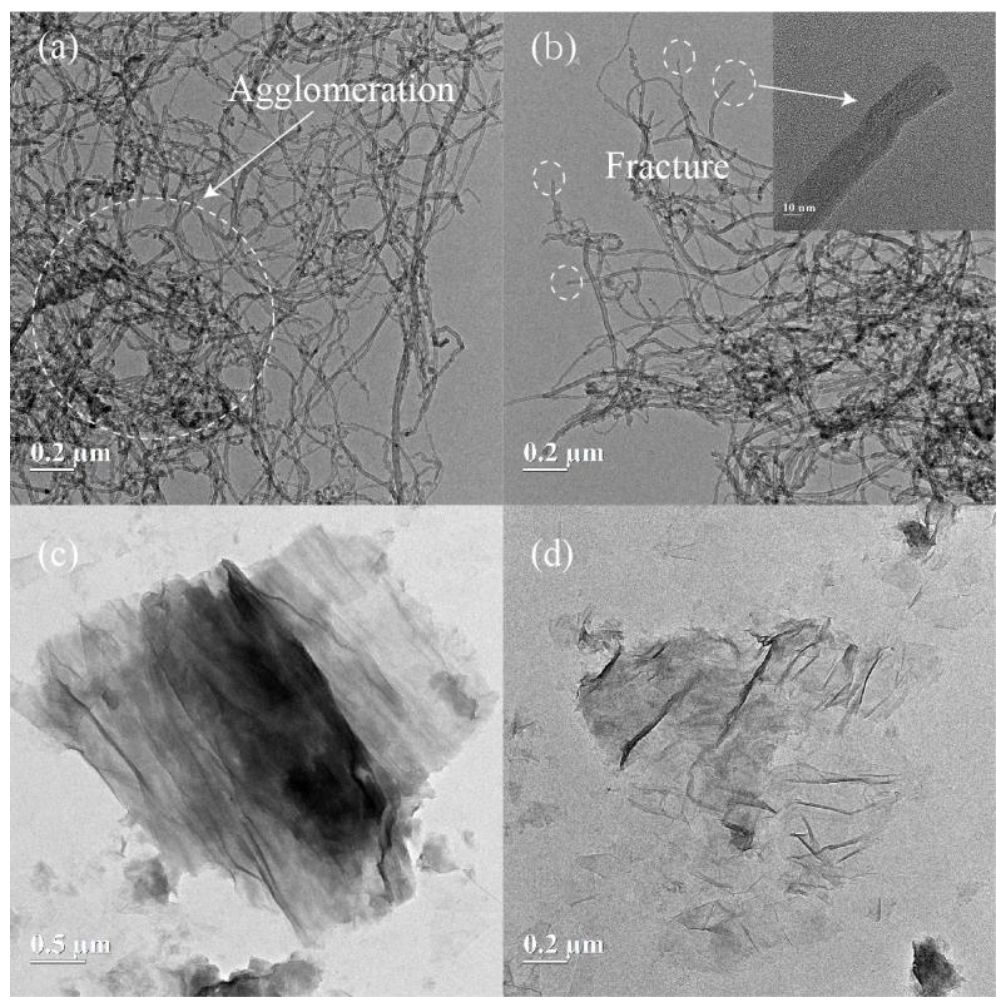

Figure 3. TEM images of the (a) CNTs, (b) FCNTs, (c) graphite, and (d) GO.

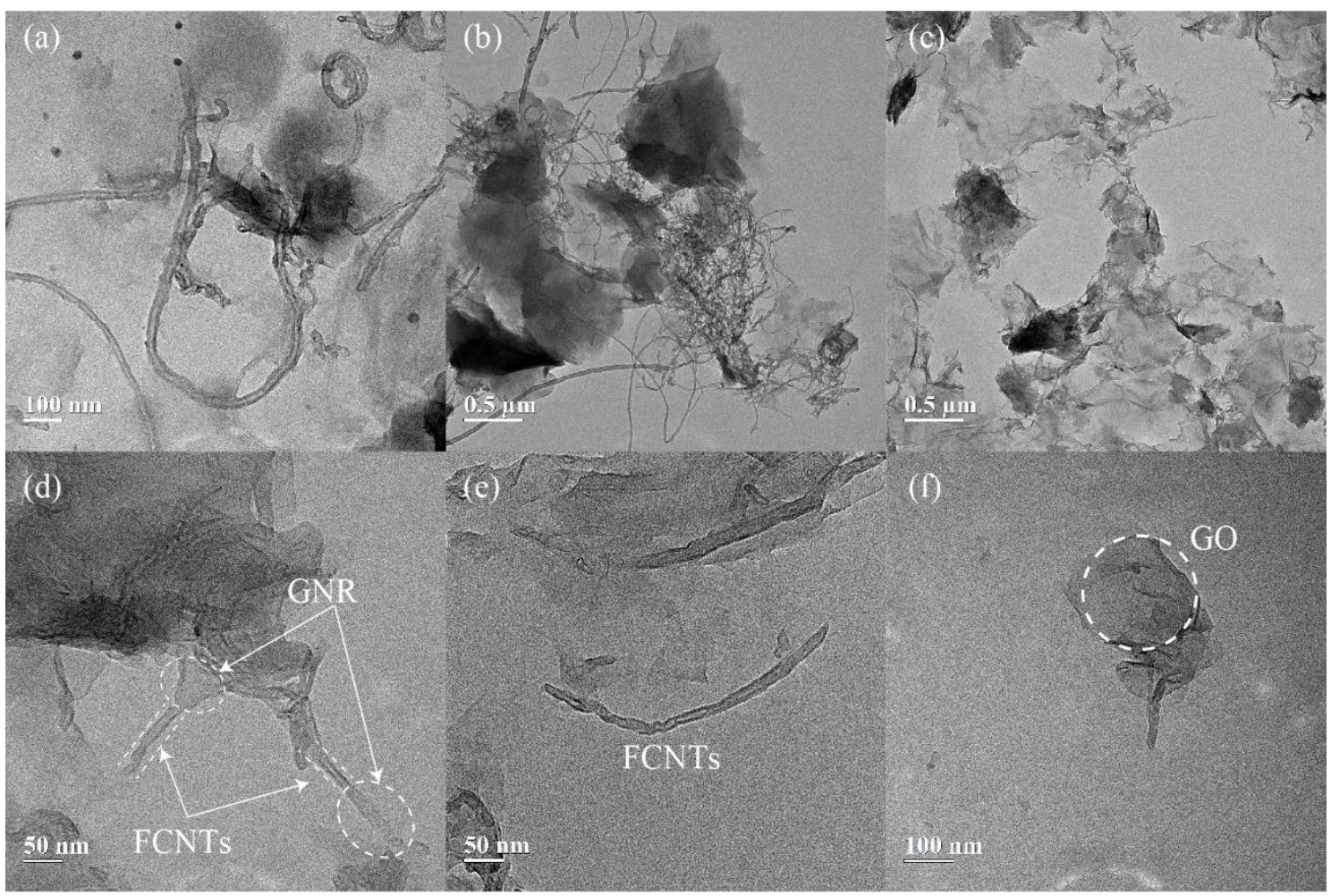

Figure 4. TEM images of the (a,b) GO/FCNTs mixture and (c-f) GNFG.

Figure 4a,b display the TEM images of the GO/FCNTs mixture, in which the GO and FCNTs were directly mixed without any chemical treatment. The results show that FCNTs are still being intertwined, with the GO and FCNTs remaining independent. Figure 4c 
depicts the overall morphological characteristics of GNFG. The FCNTs in the GNFG exhibit a shorter length, and the agglomeration degree is reduced compared with the FCNTs in the GO/FCNTs mixture. Pure CNTs are easily oxidized to FCNTs by strong oxidizing agents, such as sulfuric acid, nitric acid, and potassium permanganate [41,65]. In the synthesis of GNFG, sulfuric acid and potassium permanganate were also used; thus, FCNTs were generated. As the length of the FCNTs in GNFG shortens, the high aspect ratio decreases, reducing the entanglement and agglomeration in water.

Furthermore, as previously reported, when the amount of $\mathrm{H}_{2} \mathrm{SO}_{4}$ and $\mathrm{KMnO}_{4}$ was sufficiently high, CNTs could unzip and become graphene-oxide nanoribbons (GNR) [66]. However, in the synthesis process of GNFG, the amounts of $\mathrm{H}_{2} \mathrm{SO}_{4}$ and $\mathrm{KMnO}_{4}$ present are not enough to result in all CNTs unzipping to form GNR. Only part of the CNTs is unzipped into GNR, and the other part is oxidized to FCNTs, resulting in the formation of the unique connected structure of functionalized carbon nanotubes-graphene oxide nanoribbons (FCNTs-GNR), and the novel connected structure presented in Figure 4d. There are significant differences in the structures of GNR and FCNTs. As shown in Figure 4a,b, the walls of the FCNTs can be clearly seen. Unlike the FCNTs, the GNR in FCNTs-GNR does not have multiple layers of walls. In addition to this connected structure of FCNTs-GNR in GNFG, independently existing FCNTs and GO can also be found (Figure 4e,f). In summary, there are three types of components in GNFG: type I is FCNTs-GNR, type II is GO, and type III is FCNTs. To facilitate an interpretation of the images shown in Figure $4 \mathrm{~d}-\mathrm{f}$, a schematic of the different components of GNFG is shown in Figure 5. The dispersion performance of this novel structure may be improved because the better dispersion of GNR can restrain the strong van der Waals forces of FCNTs connected to it.

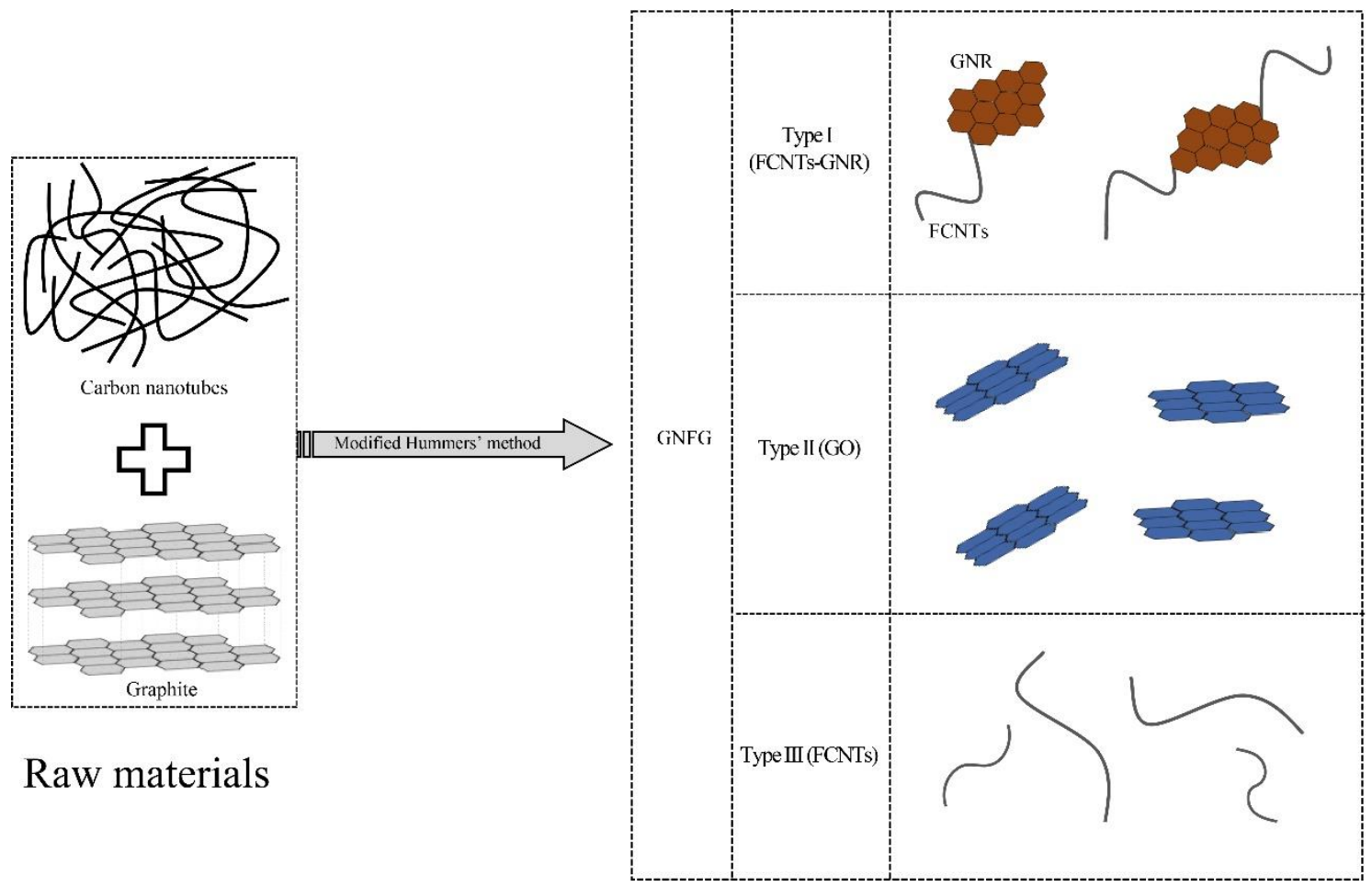

Figure 5. Schematic of the GNFG components.

\subsubsection{Determination of Crystal Structure}

The XRD patterns of graphite, GO, CNTs, FCNTs, GO/FCNTs mixture, and GNFG are presented in Figure 6. For graphite, a strong diffraction peak is observed at $2 \theta=26.38^{\circ}$ for the (002) graphitic plane, corresponding to an interlayer spacing of $0.337 \mathrm{~nm}$ (calculated using Bragg's equation). However, in the case of GO, which obtained by the chemical 
treatment of graphite, the XRD peak is observed at a different position. Compared with graphite, the diffraction peak at $2 \theta=26.38^{\circ}$ disappeared, and a new enlarged peak appeared at approximately $2 \theta=13.1^{\circ}$ (interlayer spacing $0.675 \mathrm{~nm}$ ) for the (001) crystal plane. This indicated that the crystal structure changed after the oxidization of graphite, resulting in an increased interlayer spacing. Sharma [47] suggested that an increase in the interlayer spacing was due to the insertion of oxygen-containing functional groups into the carbon atom layer. For the CNTs and FCNTs, a strong diffraction peak at $2 \theta=25.58^{\circ}$ is observed for the (002) plane with an interlayer spacing of $0.347 \mathrm{~nm}$. The FCNTs, as the oxidation product of the CNTs, did not exhibit an altered structure compared to the CNTs; therefore, there were no significant differences in the XRD patterns. The XRD pattern of GNFG shows two small peaks, a (001) diffraction peak at $2 \theta=10.17^{\circ}$ with an interlayer spacing of $0.868 \mathrm{~nm}$ and a (002) diffraction peak at $2 \theta=22.82^{\circ}$ corresponding to an interlayer spacing of $0.389 \mathrm{~nm}$. This diffuse peak at $2 \theta=22.82^{\circ}$ is also similar to the previous study [67]. To highlight the difference in GNFG, the XRD pattern of the GO/FCNTs mixture is also shown. For the GO/FCNTs mixture, unique diffraction peaks were preserved. The (002) diffraction peak of the FCNTs appears at $2 \theta=25.58^{\circ}$; however, the (001) diffraction peak of GO is shifted to the left and appears at $2 \theta=10.32^{\circ}$. This indicates that the interlayer spacing of GO in the GO/FCNTs mixture increased. Wang [68] reported that CNTs can be dispersed relatively well between GO sheets through uniform mixing of GO/CNTs, resulting in an increase in the GO layer spacing. Besides the differences in their crystal structures, there are some other differences based on their chemical functional groups. Thus, the functional groups of these materials were analyzed by FTIR and were discussed in detail in the next section.

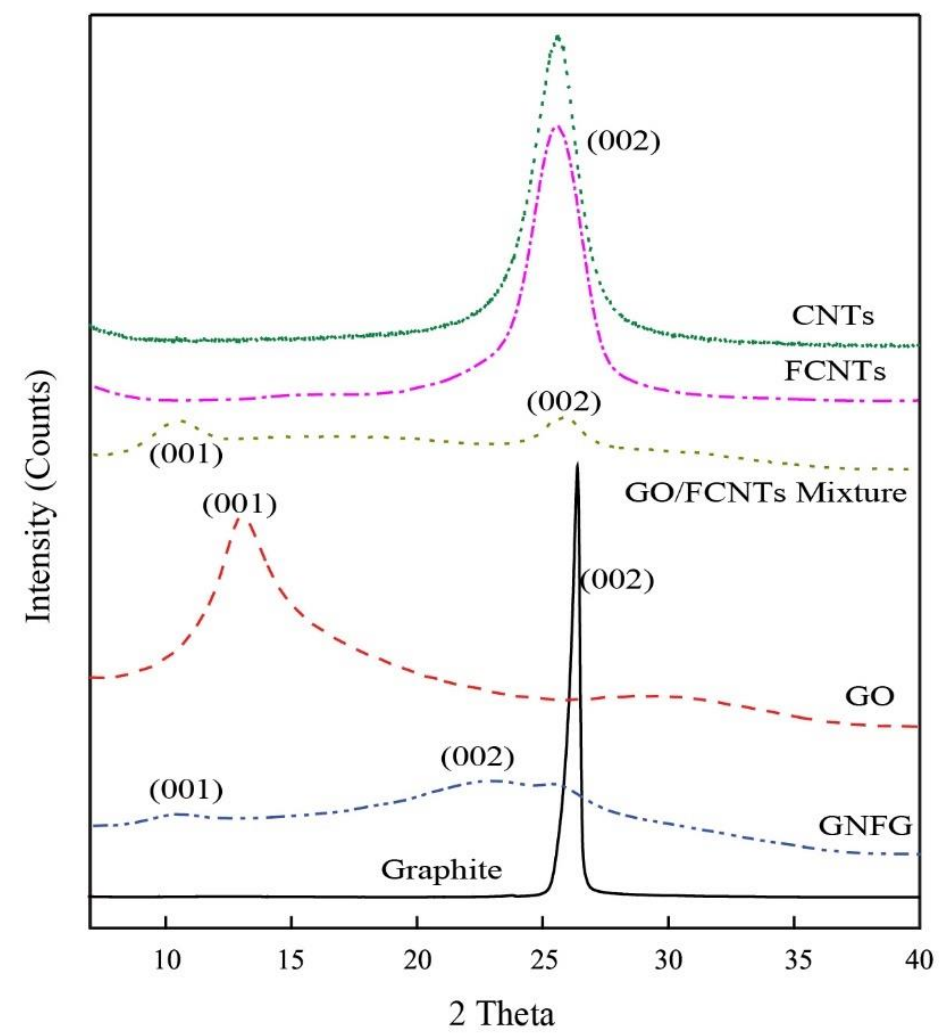

Figure 6. XRD patterns of the graphite, GO, CNTs, FCNTs, GO/FCNTs mixture, and GNFG.

\subsubsection{FTIR Spectroscopy}

The FTIR spectra of the graphite, GO, CNTs, FCNTs, GO/FCNTs mixture, and GNFG is shown in Figure $7 \mathrm{a}, \mathrm{b}$. There is a small peak arising from the $\mathrm{C}=\mathrm{C}$ stretching vibration of graphite at $1542 \mathrm{~cm}^{-1}$ in the graphite spectrum [47,69]. In addition, owing to the purity of the graphite, there is a $\mathrm{C}=\mathrm{O}$ stretching vibration peak at approximately 
$1734 \mathrm{~cm}^{-1}$ [47,69]. However, there are various functional groups in the GO structure after the graphite-oxidation treatment, including peaks for the -OH group at $3350 \mathrm{~cm}^{-1}$ and the $\mathrm{C}=\mathrm{O}$ at $1702 \mathrm{~cm}^{-1}$ [47]. Moreover, an absorption peak for the $\mathrm{C}=\mathrm{C}$ stretch is observed at approximately $1560 \mathrm{~cm}^{-1}[47,69]$. The peaks at 1153 and $1016 \mathrm{~cm}^{-1}$ correspond to the stretching vibrations of $\mathrm{C}-\mathrm{O}-\mathrm{C}$ and $\mathrm{C}-\mathrm{O}$, respectively $[47,69]$. Since the functional groups were inserted into the graphite atomic layer, the layer spacing of GO increased; this was also evidenced by XRD results. Furthermore, a peak is observed in the CNTs spectra at $1517 \mathrm{~cm}^{-1}$, which is related to aromatic $C=C$ bonds $[47,69]$. After oxidation, although the XRD patterns do not differ significantly, the functional groups of the FCNTs and CNTs are quite distinct. FCNTs have a $C=C$ stretching vibration peak at $1518 \mathrm{~cm}^{-1}$, and $-\mathrm{OH}$ and $\mathrm{C}-\mathrm{O}-\mathrm{C}$ peaks at 3339 and $1108 \mathrm{~cm}^{-1}$, respectively. This indicates that after functionalization, oxygen-containing functional groups were inserted into the structure of the CNTs [47,69]. As for the GO/FCNTs mixture, the FTIR spectrum is similar to GO. The similarity in the spectrum is possibly attributed to the presence of GO in the GO/FCNTs mixture. In the case of GNFG, the peak appears at approximately $3353 \mathrm{~cm}^{-1}$, which corresponds to $-\mathrm{OH}$ stretching vibrations. Moreover, the peaks observed at 1697, 1548, 1147,1025 , and $848 \mathrm{~cm}^{-1}$ are related to the stretching vibrations of $\mathrm{C}=\mathrm{O}, \mathrm{C}=\mathrm{C}, \mathrm{C}-\mathrm{O}-\mathrm{C}$, $\mathrm{C}-\mathrm{O}$, and epoxy groups, respectively $[47,69]$. Due to the graphene oxide nanoribbons in the GNFG complex, the FTIR spectrum of GNFG is also similar to the pure graphene oxide nanoribbons [70]. The properties of the functional groups could also determine the dispersion and stability of the nanomaterials in aqueous solutions, as determined via UV-vis spectroscopy.
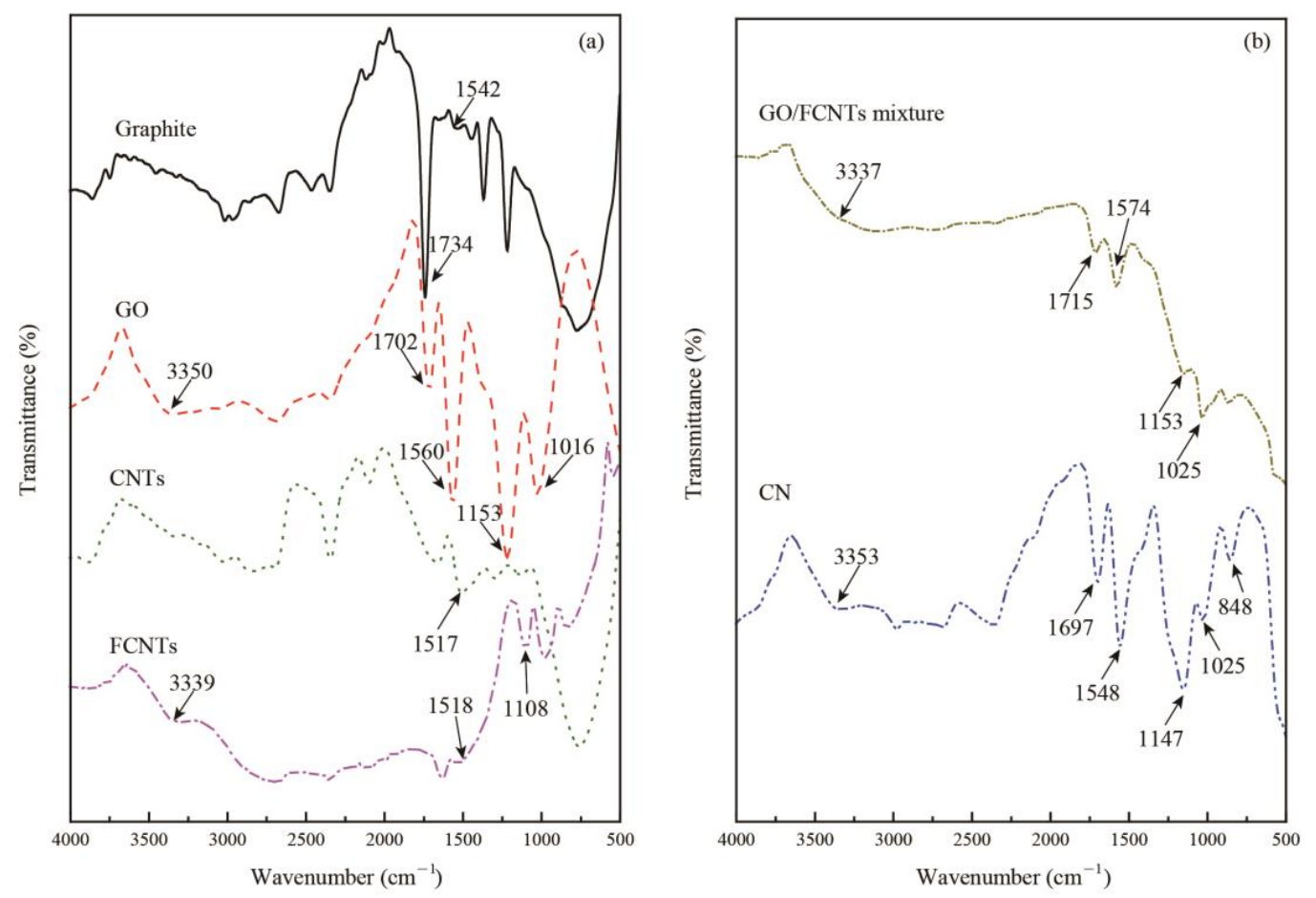

Figure 7. FTIR spectra: (a) graphite, GO, CNTs, and FCNTs, (b) GO/FCNTs mixture and GNFG.

\subsubsection{Dispersion and Stability of Nanomaterials}

To investigate the dispersion properties of GNFG in aqueous solutions, UV-vis spectroscopy was conducted on GNFG and the obtained results were compared to those of the CNTs, FCNTs, GO, and GO/FCNTs mixture (Figure 8). The absorbance is proportional to the dispersion of the nanoparticles because only uniformly dispersed nanoparticles can effectively absorb light in the UV-vis region [34]. Thus, the best dispersity in aqueous solutions was observed for GO, followed by GNFG, GO/FCNTs mixture, FCNTs, and CNTs. Owing to the high aspect ratio and strong van der Waals forces between the molecules, 
CNTs are likely to agglomerate in aqueous solutions and have poor dispersion [71]. In comparison with CNTs, the insertion of oxygen-containing functional groups results in the surface of the FCNTs being negatively charged due to the ionization, which generates electrostatic repulsion leading to improved dispersion of FCNTs in aqueous solutions [72]. As indicated in the FTIR spectra, GO contains hydrophilic oxygen-containing functional groups $(-\mathrm{OH},-\mathrm{COOH})$, which generate electrostatic repulsion, and there is no strong van der Waals forces between the GO, resulting in the best dispersion [73]. Additionally, the absorbance of the GO/FCNTs mixture is higher than those of the CNTs and FCNTs, also due to the fact that the negatively charged surfaces of the FCNTs and GO generate electrostatic repulsion, increasing the degree of dispersion [34]. However, it should be noted that the absorbance of GNFG as a complex was higher than that of the GO/FCNTs mixture. The excellent dispersion of GNFG is attributed to several characteristics. Firstly, as described in the TEM results, due to the partial unzipping of CNTs to form FCNTs-GNR, the electrostatic repulsion on the GNR surface is able to inhibit the van der Waals forces between FCNTs in FCNTs-GNR. In particular, as the length of independently-existing FCNTs in GNFG shortens and the high aspect ratio decreases, the degree of intertwining is reduced, which results in an improved dispersion of GNFG [74]. Furthermore, the electrostatic repulsion generated by the negatively charged functional groups on the surface of independently existing GO and FCNTs can effectively improve the dispersion [75,76].

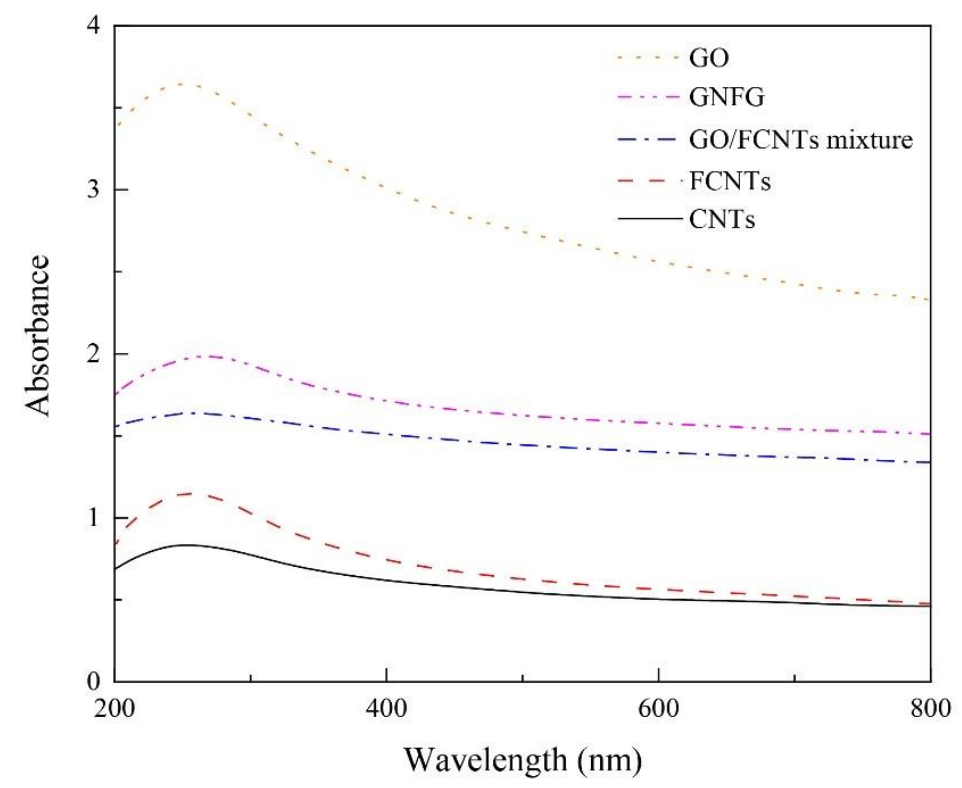

Figure 8. UV-vis spectra of the GO, CNTs, FCNTs, GO/FCNTs mixture, and GNFG.

To further evaluate the dispersion of nanomaterials in aqueous solutions, the stability of dispersion is also investigated. The dispersion stability of the CNTs, FCNTs, GO, GO/FCNTs mixture, and GNFG in aqueous solutions was determined over time after ultrasonic treatment, as shown in Figure 9. Figure 9a shows the results of observations made immediately after the ultrasonication, at which point all the nanomaterials were uniformly dispersed in the solutions and there were no clear agglomerates that precipitated out. After ten minutes (Figure 9b), the CNTs and FCNTs exhibited a different extent of agglomeration and precipitation. Although the absorbance of FCNTs in the UV-vis was higher than that of the CNTs, the stability of FCNTs in an aqueous solution was still unsatisfactory. However, the GO/FCNTs mixture, GO, and GNFG were still uniformly dispersed in the aqueous solution. After $6 \mathrm{~h}$, the FCNTs and CNTs were completely agglomerated and precipitated out of the solution (Figure 9c). Furthermore, the color of the solution containing the GO/FCNTs mixture became lighter, indicating that the mixture of GO/FCNTs almost completely precipitated out of the solution. The GNFG remained 
partially and steadily dispersed in the solution, while GO remained steadily dispersed. After $24 \mathrm{~h}$, only GO was still partially dispersed in the aqueous solution.
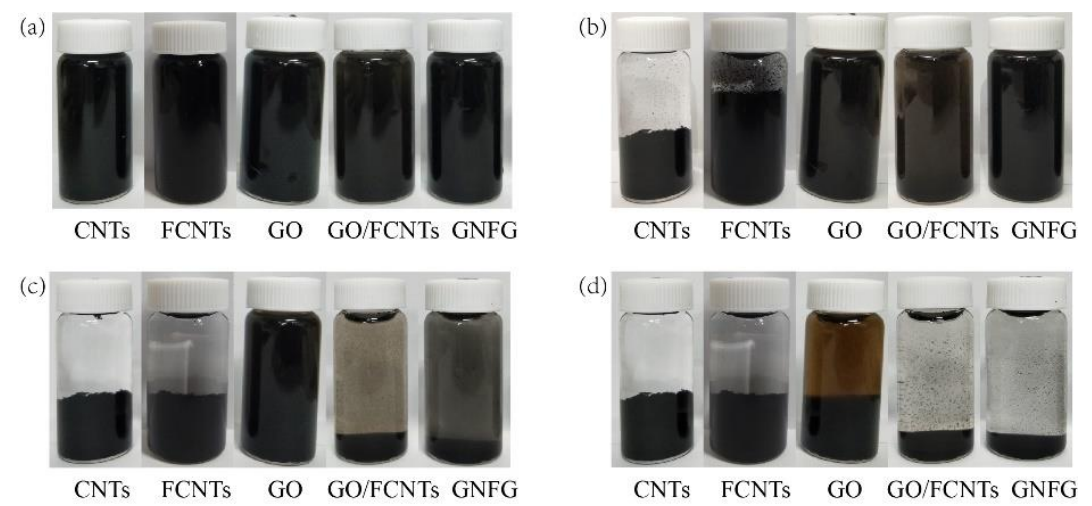

Figure 9. Dispersion of the nanomaterials over time after the ultrasonic treatment: (a) $0 \mathrm{~min}$, (b) $10 \mathrm{~min}$, (c) $6 \mathrm{~h}$, and (d) $24 \mathrm{~h}$.

Although the preparation of the GO/FCNTs mixture is simple and the dispersion of the GO/FCNTs mixture is better than that of the CNTs and FCNTs, it is still less stable. However, chemically-treated GNFG not only has better dispersion in aqueous solutions, but also has a better stability. This also provided a guarantee that GNFG would show a reinforcement effect in cement-based materials. The advantages of GNFG as a reinforcing agent for cementitious systems will be further discussed in the following sections.

\subsection{Mechanical Properties}

The effects of different nanomaterials (GO, CNTs, GO/FCNTs mixture, and GNFG) on the mechanical properties of hardened cement paste were assessed after 1, 3, 7, and 28 days. Figure $10 \mathrm{a}, \mathrm{b}$ represent the compressive and splitting tensile strength of the cement paste with and without GO, CNTs, GO/FCNTs mixture, and GNFG, respectively. In comparison with OPC, after 28 days of curing, it was evidenced that incorporating $0.05 \mathrm{wt} . \%$ CNTs led to an increase in both the compressive strength (6.65\%) and splitting tensile strength (15.39\%) of the cement paste. Moreover, the addition of $0.05 \mathrm{wt} . \% \mathrm{GO}$ increased the compressive and splitting tensile strengths of the cement paste by $2.98 \%$ and $11.76 \%$, respectively, after 28 days of curing. This indicates that CNTs and GO can improve the mechanical properties of cement paste, which agrees with previous reports [77]. Addition of CNTs and GO increase the mechanical strength of the cement paste based on the following effects: (1) the filling effect, in which the CNTs and GO function as fillers in the nanoscale pores of the cement matrix; (2) the bridging effect, in which the nanomaterials connect the microcracks in the cement and inhibit the development of cracks; and (3) the nucleation effect, in which the nanomaterials provide more nucleation sites for hydration of the cement paste $[30,78,79]$. Further, when $0.05 \mathrm{wt} . \%$ of the GO/FCNTs mixture was added to the cement paste, the compressive and splitting tensile strengths were improved by $16.5 \%$ and $15.6 \%$, respectively, fully demonstrating the synergistic effect of GO and FCNTs, as previously reported [34].

Notably, after hydration for 28 days, the $0.05 \mathrm{wt} . \%$ GNFG specimen showed the highest compressive strength (123.87 MPa) and splitting tensile strength (5.25 MPa), which were improved by $25.39 \%$ and $17.31 \%$, respectively, compared to OPC. GNFG appeared to improve the mechanical properties of the cement paste, possibly because of the good dispersion and unique connected structure. Although GO has better dispersion in aqueous solutions than GNFG, the co-effect of GNFG can significantly improve the mechanical properties of the cement paste. 

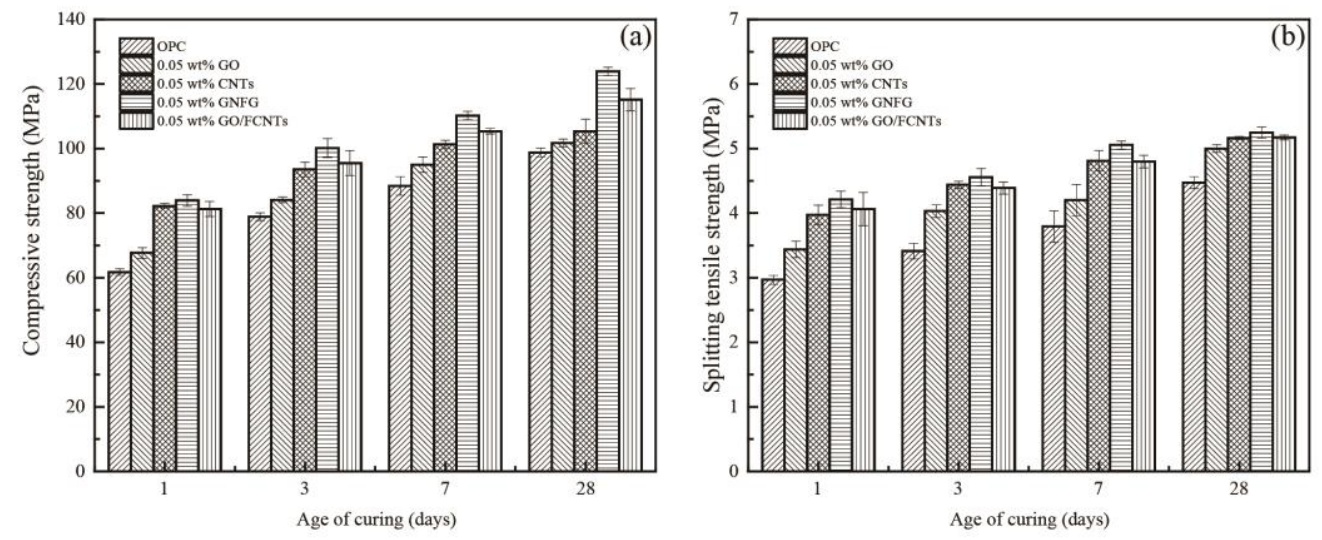

Figure 10. (a) Compressive and (b) splitting tensile strength of the specimens.

\subsection{Microstructure Observations}

A previous study [80] showed that the mechanical strength of nanomaterial-incorporated hardened cement paste is related to its microstructure. Therefore, the microstructure of the fractured surface of hardened cement paste with and without nanomaterials, after 28 days of curing, was observed via SEM. Figure 11a,b show the SEM images of OPC as the control sample. For the cement composites without any nanomaterials, the cement matrix structure is not compact and porous, with several microscale pores and cracks that lead to relatively poor mechanical properties for OPC compared to nanomaterial-incorporated cement pastes.

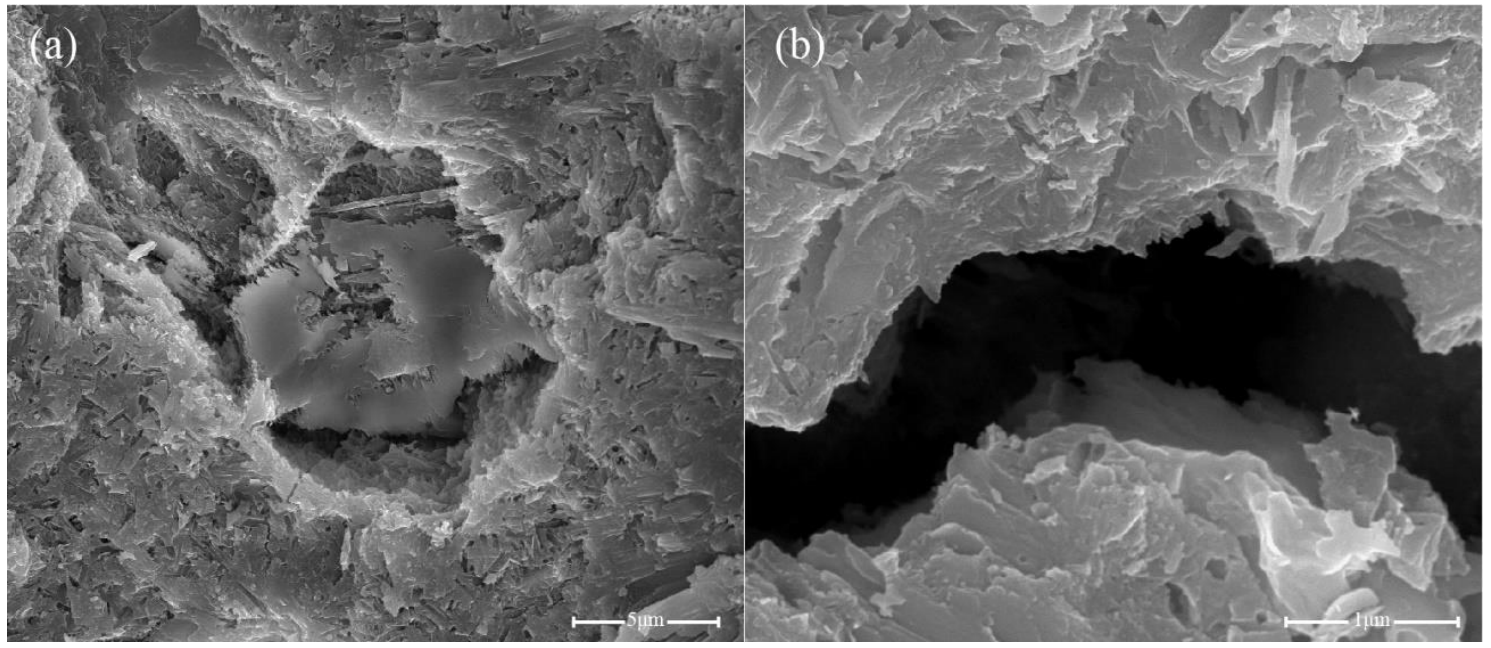

Figure 11. SEM images of OPC $(\mathbf{a}, \mathbf{b})$.

Compared to OPC, the microstructure of the 0.05 wt.\% GO specimen (Figure 12a,b) is relatively compact, with reduced microscale cracks. GO can fill the microscale pores and cracks and provide more nucleation sites for cement hydration, thereby improving the microstructure of the cement. The addition of $0.05 \mathrm{wt}$. $\%$ CNTs resulted in a more uniform and compact structure, as the CNTs generated bridges between the cement hydrates, as shown in Figure 13. Previous studies [81-83] have already confirmed that the bridging effect of CNTs improves the load-bearing capacity of the cement matrix. In contrast, CNTs also show outstanding filling effects; they can fill the microscale pores and increase the compactness of the cement matrix. However, although CNTs can improve the microstructure of the cement, CNTs tend to agglomerate in the cement matrix (Figure 13a), which could interfere with its excellent mechanical properties. In addition, Figure 14a,b present the microstructure of cement paste with $0.05 \mathrm{wt}$ \% GO/FCNTs mixture. It can be seen 
that the cement matrix of $0.05 \mathrm{wt} . \% \mathrm{GO} / \mathrm{FCNTs}$ mixture is compact, and some hydration products are covered on the surface of the cement matrix. Besides, the FCNTs exhibit a lower degree of agglomeration and are filled in the cement matrix.

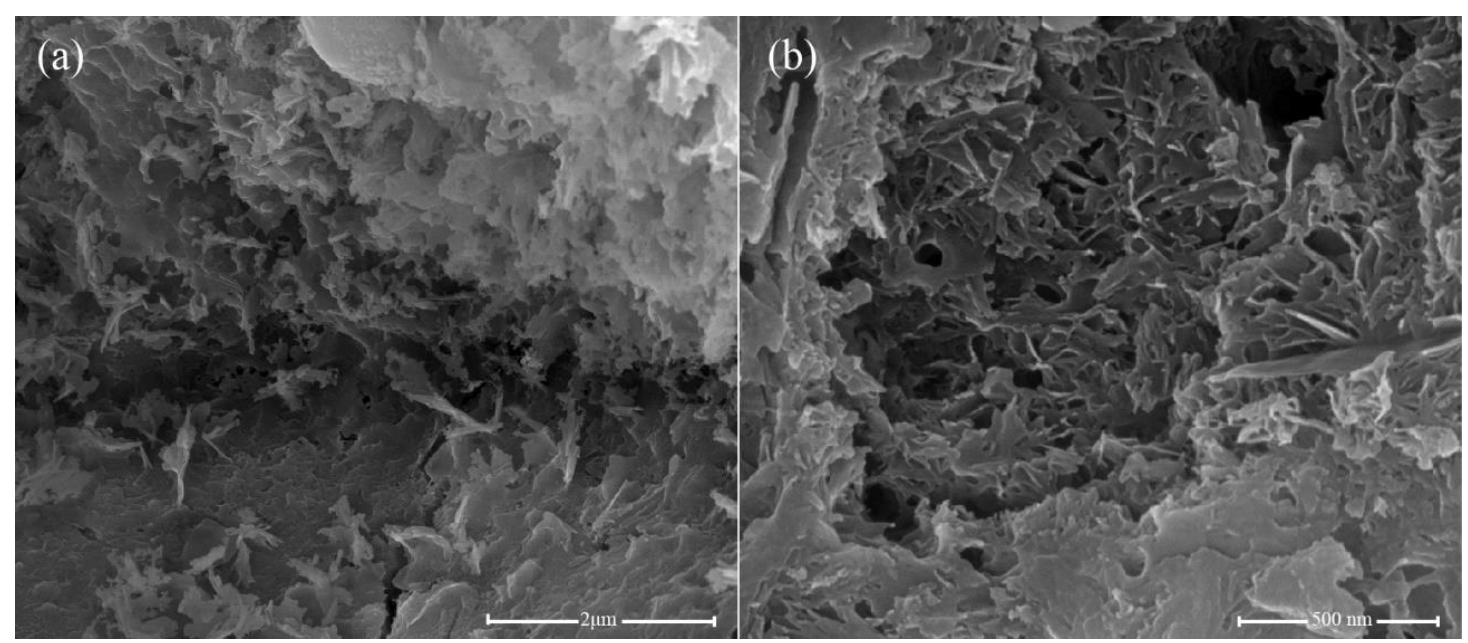

Figure 12. SEM images of 0.05 wt. $\%$ GO (a,b).

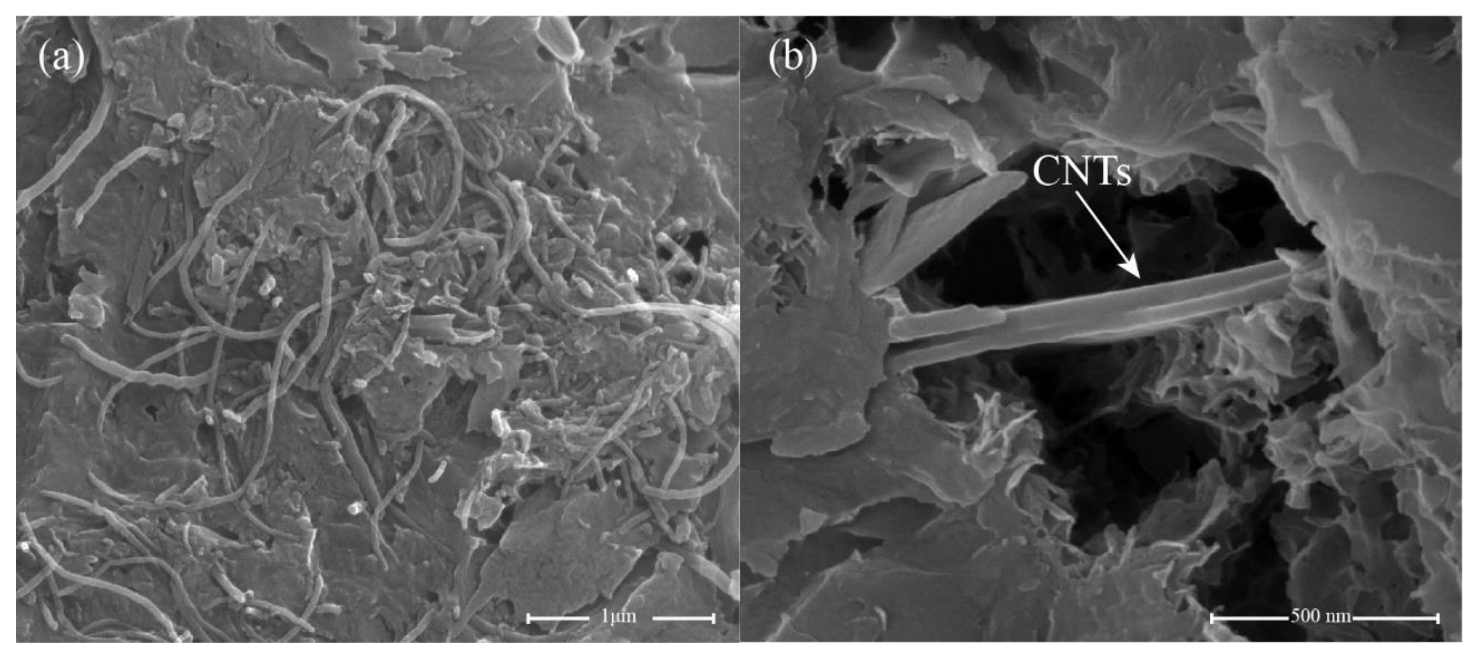

Figure 13. SEM images of 0.05 wt. $\%$ CNTs $(\mathbf{a}, \mathbf{b})$.

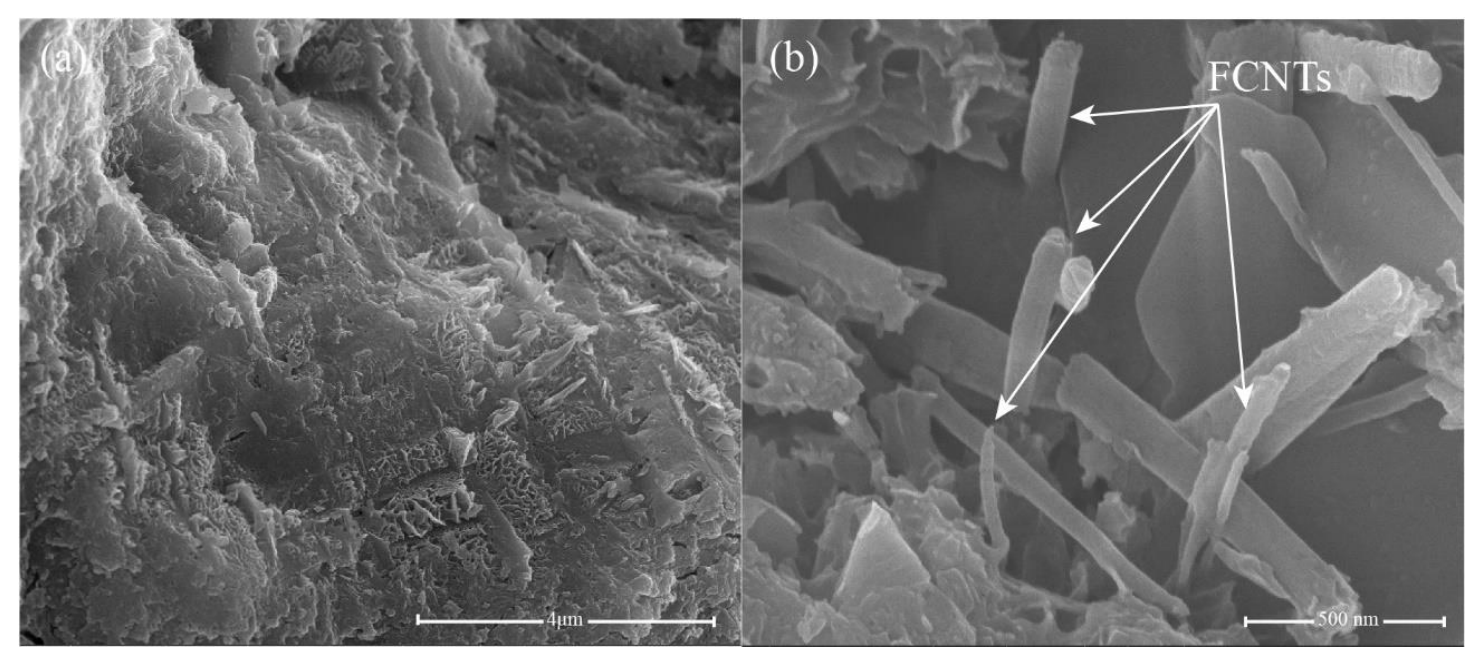

Figure 14. SEM images of $0.05 \mathrm{wt} . \% \mathrm{GO} / \mathrm{FCNTs}(\mathbf{a}, \mathbf{b})$. 
The microstructures of the cement hydrates containing $0.05 \mathrm{wt}$.\% GNFG after 28 days of hydration are shown in Figure 15. It is clear that hydration products of calcium-silicatehydrate (C-S-H) are uniformly distributed in the matrix without any large pores, as shown in Figure 15a. Moreover, in the 0.05 wt.\% GNFG specimen, aggregation of FCNTs is not observed in the cement matrix. The GNFG can fill the microscale pores in the cement matrix and play a bridging role (Figure 15b). In addition, GNFG is able to bridge surficial $\mathrm{Ca}^{2+}$ of the cement matrix due to its wrinkled surface with oxygen-containing functional groups which enhances the interfacial bonding [84]. This also contributes to the very dense microstructure of cement paste and the $0.05 \mathrm{wt}$ \% GNFG-incorporated specimen exhibiting the highest compressive strength and splitting tensile strength among the five groups.

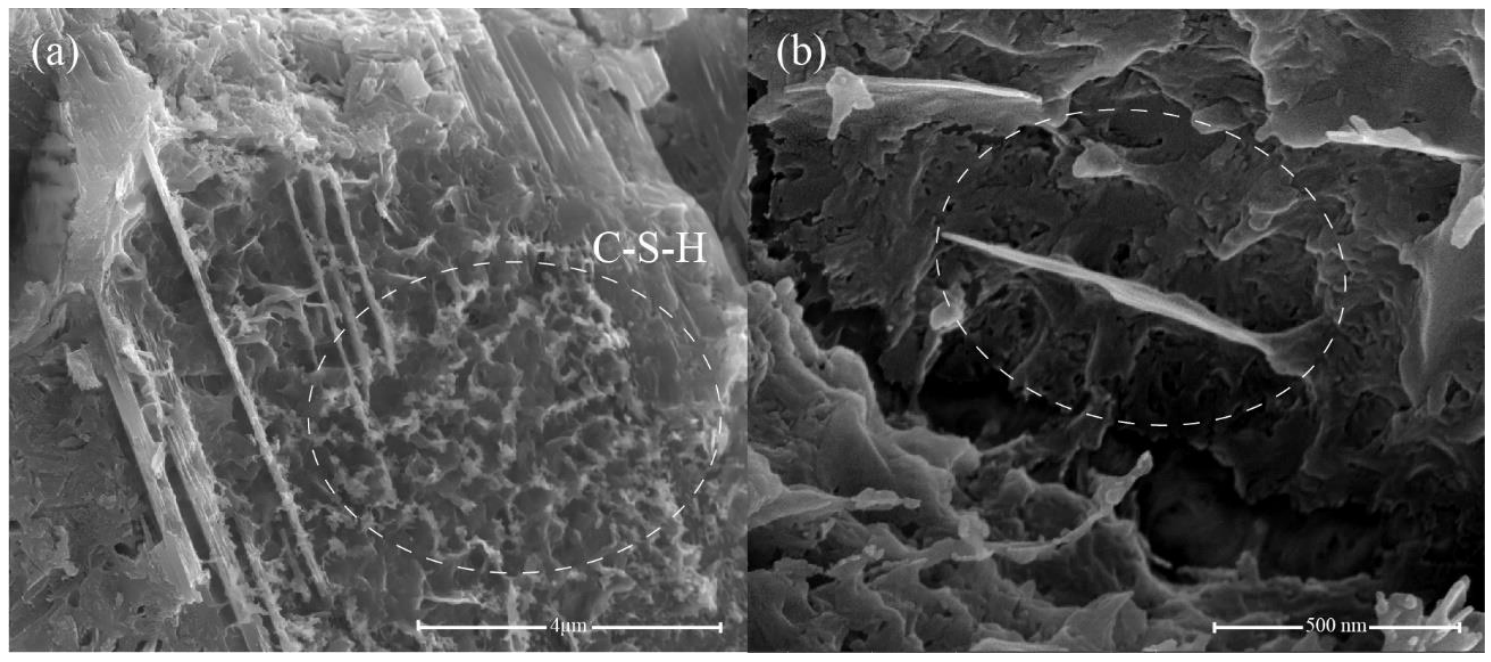

Figure 15. SEM images of 0.05 wt. $\%$ GNFG $(\mathbf{a}, \mathbf{b})$.

\subsection{Heat of Hydration}

Nanomaterials have a significant effect on the early hydration process of cementitious systems [85]. To fully observe and compare the effects of the different carbon nanomaterials on the early hydration process (within $72 \mathrm{~h}$ ) of cement, isothermal calorimetry was used to evaluate the amount of heat released from the OPC and cement pastes containing $0.05 \mathrm{wt} \%$ GO, CNTs, GO/FCNTs mixture, and GNFG (Figure 16a,b). Typically, exothermic reactions with four stages can be observed during the hydration process of the cement: the first stage is the initial period, the second stage is the induction period, the third stage is the acceleration period, and the fourth stage is the deceleration period [86,87]. Previous studies have shown that the SP delays the induction period [88]. The SP, as an anionic surfactant, will be more easily adsorbed on the surface of an oppositely charged cement. Thus, due to adding the SP to the cement paste, the surface of the cement particles was covered, which hindered the exchange of ions in the hydration system and reduced the hydration rate. In addition, the interaction between $\mathrm{Ca}^{2+}$ and the SP reduces the concentration of $\mathrm{Ca}^{2+}$, and hinders the nucleation of hydration products $[89,90]$. However, the five groups of specimens in this study contain the same content of SP, the delayed effect of SP on the early induction period of hydration can be ignored. 

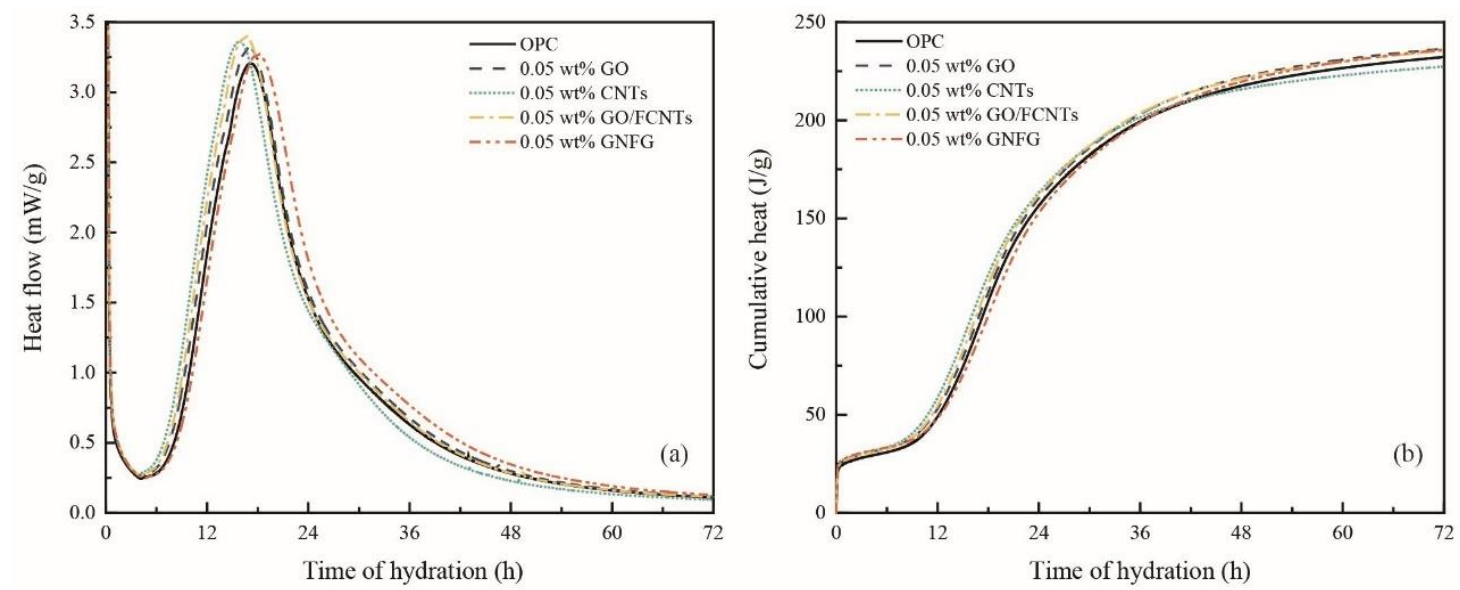

Figure 16. (a) Heat flow curves and (b) cumulative heat curves of the cement paste specimens.

As shown in Figure 16a, although the addition of different nanomaterials, there was no significant influence on the initial and induction periods of the cement hydration process. However, from about four hours, the hydration reaction enters an acceleration period. It can be clearly observed that the maximum heat flow of the cement paste with nanomaterials is higher than that of OPC. Therefore, these carbon nanomaterials contribute obviously to the hydration of cement, which is also consistent with previous studies [91]. When all samples entered the deceleration period, it was found that the cement paste incorporating GNFG had a higher heat flow during the deceleration period compared to the other samples. Although the maximum heat flow of GNFG is slightly lower than that of specimens with other nanomaterials, the higher heat flow during the deceleration period results in a cumulative heat of $72 \mathrm{~h}$ that is not significantly different from that of specimens with other nanomaterials. In addition, it could also be found that the heat flow of the samples containing $0.05 \mathrm{wt} . \%$ CNTs was lower than all samples in the deceleration period and resulted in the lowest cumulative heat over $72 \mathrm{~h}$ (Figure 16b). This is attributed to the agglomeration of CNTs in the cement matrix as presented in the SEM image (Figure 13a), which has an impact on the deceleration period of the hydration reaction. Overall, owing to the addition of the nanomaterials (besides CNTs), the cumulative heat of the cement hydration increased after $72 \mathrm{~h}$, indicating the enhanced degree of hydration of the cement at early stage. However, although CNTs promote the hydration reaction during the acceleration period, they also have some impact on the hydration reaction during the deceleration period. It is difficult to evaluate the degree of hydration of different samples at various periods by only using calorimetry. Therefore, $\mathrm{XRD}$ and TG analysis also were applied to investigate the effects of the CNTs, GO, GO/FCNTs mixture, and GNFG on the hydration reaction of cement pastes at various curing times.

\subsection{XRD Analysis of the Hydration Products}

XRD was employed to qualitative analyze the hydration products and the consumption rate of the anhydrous phases at different hydration periods [92]. Previous research indicated that owing to the large specific surface area of CNTs and GO, more nucleation sites are present for cement hydration and more hydration products are generated $[10,93]$. The XRD patterns of OPC and the cement pastes containing $0.05 \mathrm{wt} . \% \mathrm{GO}, 0.05 \mathrm{wt} . \% \mathrm{CNTs}$, 0.05 wt.\% GO/FCNTs mixture, and 0.05 wt.\% GNFG are shown in Figure 17. Usually, as the hydration reaction progresses, the unhydrated calcium silicate content gradually decreases [94]. As reported previously [95-97], the peaks of $C_{3} S$ and $C_{2} S$ overlap with those of the other minerals (C-S-H, calcium hydroxide (CH), and calcite). In Figure 17, the peaks of $\mathrm{C}_{3} \mathrm{~S}$ and $\mathrm{C}_{2} \mathrm{~S}$ also appear to overlap; thus, it was not easy to determine the changes in reduction. 

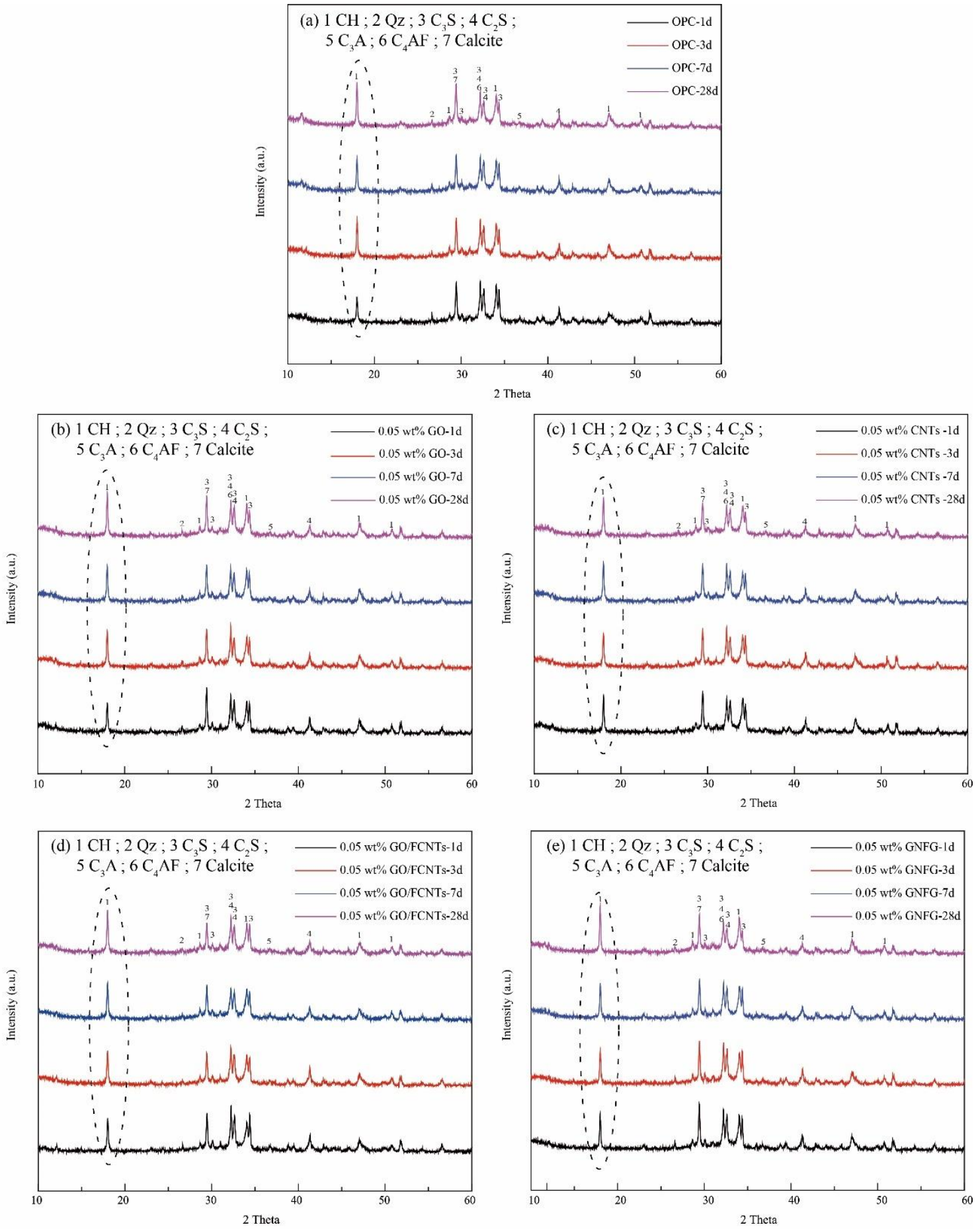

Figure 17. XRD spectra of (a) OPC, (b) 0.05 wt. \% GO, (c) 0.05 wt.\% CNTs, (d) 0.05 wt.\% GO/FCNTs. and (e) 0.05 wt. $\%$ GNFG.

It is well known that $\mathrm{C}-\mathrm{S}-\mathrm{H}$ and $\mathrm{CH}$ are produced simultaneously by the hydration of calcium silicate $[47,98]$. The relative hydration rate can be established by measuring the content of $\mathrm{C}-\mathrm{S}-\mathrm{H}$ or $\mathrm{CH}$. In general, $\mathrm{XRD}$ is used to determine the $\mathrm{CH}$ content instead of the $\mathrm{C}-\mathrm{S}-\mathrm{H}$ content because $\mathrm{CH}$ has a hexagonal crystal structure that can be easily detected by XRD. In contrast, the $\mathrm{C}-\mathrm{S}-\mathrm{H}$ phase forms a semi-crystalline or amorphous phase, which limits the use of XRD as a detection technique [47,99-101]. In the crystallization patterns (Figure 17), the diffraction peaks of $\mathrm{CH}$ were observed at $2 \theta=17.9^{\circ}, 28.6^{\circ}, 34.1^{\circ}, 47.1^{\circ}$, and $50.1^{\circ}$ [47]. For the OPC, $0.05 \mathrm{wt} . \% \mathrm{GO}, 0.05 \mathrm{wt} . \%$ CNTs, $0.05 \mathrm{wt} . \% \mathrm{GO} / \mathrm{FCNTs}$ mixture, and $0.05 \mathrm{wt} . \%$ GNFG specimens, the $\mathrm{CH}$ diffraction peaks show significant differences. The 
XRD patterns of the five groups show that the $0.05 \mathrm{wt} . \%$ GNFG specimen has the highest $\mathrm{CH}$ intensity over the different periods, which indicates that GNFG improves the degree of hydration of cement paste and more hydration products are produced compared to OPC. In addition, when $0.05 \mathrm{wt} . \% \mathrm{CNTs}, \mathrm{GO}$, and GO/FCNTs mixture were added to the cement, the $\mathrm{CH}$ content also increased. This indicates that hydration was promoted when these nanomaterials were used. The amounts of $\mathrm{CH}$ in each sample at the different periods were quantified by TG analysis.

\subsection{Thermogravimetric Analysis}

The OPC, 0.05 wt. $\%$ GO, 0.05 wt. $\%$ CNTs, 0.05 wt. $\%$ GO/FCNTs mixture, and 0.05 wt. $\%$ GNFG samples were analyzed by TG and DTG at 1, 3, 7, and 28 days, as shown in Figure 18. The mass loss at approximately $100^{\circ} \mathrm{C}$ is related to the evaporation of free water. Mass loss in the range of $400-500{ }^{\circ} \mathrm{C}$ is due to the decomposition of $\mathrm{CH}$, and between 600 and $700{ }^{\circ} \mathrm{C}$ is attributed to calcium carbonate $\left(\mathrm{CaCO}_{3}\right)$ decomposition [102]. However, as stated in the XRD section, calcium silicates produce both C-S-H and $\mathrm{CH}$ when hydrated [47]. Based on the values in Figure 18, the $\mathrm{CH}$ content for each sample at the different curing times was calculated according to Equation (1). $\mathrm{WL}_{\mathrm{Ca}(\mathrm{OH})_{2}}$ represents the percentage weight loss of $\mathrm{CH}$, and $\mathrm{m}_{\mathrm{Ca}(\mathrm{OH})_{2}}$ and $\mathrm{m}_{\mathrm{H}_{2} \mathrm{O}}$ are the molecular masses of portlandite $(74 \mathrm{~g} / \mathrm{mol})$ and water $(18 \mathrm{~g} / \mathrm{mol})$, respectively. The calculation results are listed in Table 6 .

$$
\mathrm{Ca}(\mathrm{OH})_{2, \text { measured }}=\mathrm{WL}_{\mathrm{Ca}(\mathrm{OH})_{2}} \times \mathrm{m}_{\mathrm{Ca}(\mathrm{OH})_{2}} / \mathrm{m}_{\mathrm{H}_{2} \mathrm{O}} .
$$

Table 6. Percentage content $(\%)$ of $\mathrm{Ca}(\mathrm{OH})_{2}$ in the hardened cement paste after different curing times.

\begin{tabular}{ccccc}
\hline Specimen & \multicolumn{3}{c}{$\mathbf{C a}(\mathbf{O H})_{\mathbf{2}}$ Content (\%) } \\
\cline { 2 - 4 } & 1 Day & 3 Days & 7 Days & 28 Days \\
\hline OPC & $5.43 \%$ & $6.42 \%$ & $7.23 \%$ & $7.44 \%$ \\
0.05 wt. $\%$ GO & $6.17 \%$ & $6.50 \%$ & $7.46 \%$ & $7.62 \%$ \\
0.05 wt. $\%$ CNTs & $6.29 \%$ & $6.81 \%$ & $8.43 \%$ & $10.03 \%$ \\
0.05 wt. $\%$ GO/FCNTs & $6.83 \%$ & $8.54 \%$ & $9.35 \%$ & $10.27 \%$ \\
0.05 wt. $\%$ GNFG & $8.62 \%$ & $9.49 \%$ & $9.66 \%$ & $10.97 \%$ \\
\hline
\end{tabular}

As shown in Figure 18 and Table 6, compared with the samples containing 0.05 wt.\% CNTs, GO, GO/FCNTs mixture, and GNFG, OPC showed the lowest relative amount of $\mathrm{CH}(1 \mathrm{~d}: 5.43 \%$; $3 \mathrm{~d}: 6.42 \%$; $7 \mathrm{~d}: 7.23 \%$; and $28 \mathrm{~d}: 7.44 \%$ ) for each period. This indicates that OPC has fewer hydration products and shows a lower degree of hydration, which is also consistent with the XRD results. For the samples with nanomaterials, the hydration of the cement paste was enhanced at each curing time, although the degree of enhancement differed. Using a dosage of $0.05 \mathrm{wt} . \%$, GNFG induces the greatest enhancement in hydration among the four nanomaterials, followed by the GO/FCNTs mixture, CNTs, GO, and OPC. This also proves that GNFG can promote the hydration of cement paste and generate more hydration products, and the promotion effect is better than other nanomaterials. 

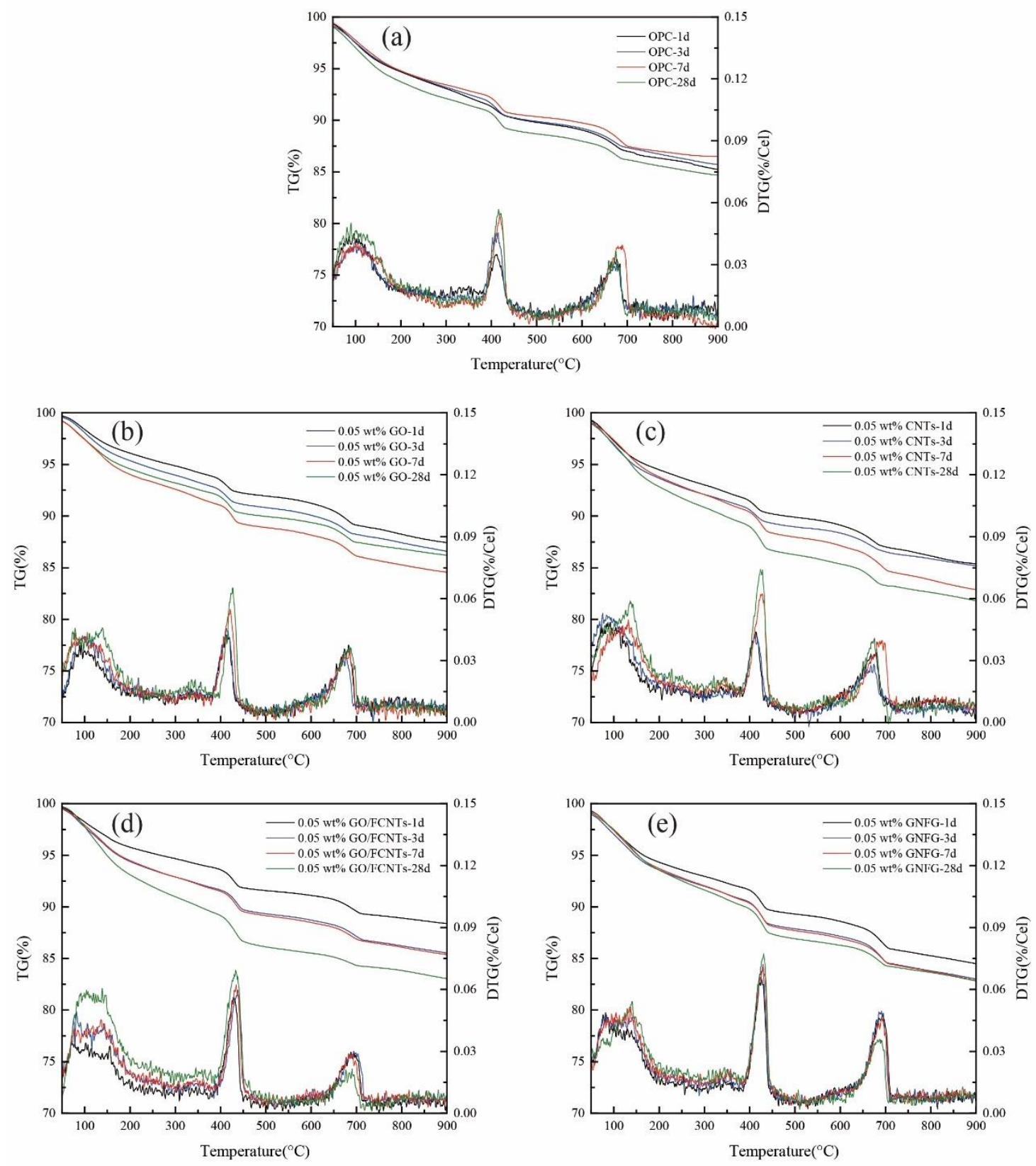

Figure 18. TG/DTG curves of the samples containing (a) OPC, (b) 0.05 wt.\% GO, (c) 0.05 wt.\% CNTs, (d) 0.05 wt.\% GO/FCNTs, and (e) 0.05 wt.\% GNFG.

\section{Conclusions}

In this study, the highly-dispersed GNFG was hydrothermally synthesized and its effects on the mechanical properties, hydration kinetics, hydration products, and microstructure of cementitious composites were investigated. The results were compared with those using the composites incorporating other typical carbon nanomaterials. Based on the experimental results, the following conclusions can be drawn:

(1) GNFG, as a new carbon nanomaterial, was successfully synthesized via a chemical method, and there are three different components (FCNTs-GNR, FCNTs, and GO) of GNFG due to the treatment conditions and led to better dispersibility.

(2) Although the GO, CNTs, GO/FCNTs mixture, and GNFG improved the compressive and splitting tensile strength of cement paste at the same content $(0.05 \mathrm{wt} . \%)$, GNFG induced the greatest improvement in the mechanical properties of the cement paste due to the denser microstructure. 
(3) GNFG, as a new reinforcing nanomaterial for cementitious systems, similar to other nanomaterials, can fill cracks and play a bridging role in the cement matrix.

(4) GNFG can increase the maximum heat flow and cumulative heat of cement hydration reaction, promote the hydration reaction and generate more hydration products.

These experimental results demonstrate that GNFG exhibits excellent potential as a new nano-reinforcing agent for cementitious materials, especially relating to the improvement in the mechanical properties of cementitious composites.

Author Contributions: Conceptualization, S.L., E.Z.N. and S.B.; formal analysis, P.L. and S.H.; resources, S.B.; writing-original draft preparation, P.L. and J.L.; writing-review and editing, S.L., E.Z.N. and S.B.; supervision, S.L., E.Z.N. and S.B. All authors have read and agreed to the published version of the manuscript.

Funding: This work is supported by the Korea Agency for Infrastructure Technology Advancement(KAIA) grant funded by the Ministry of Land, Infrastructure, and Transport (Grant 21NANOB156177-02).

Data Availability Statement: Data are contained within the article.

Conflicts of Interest: The authors declare no conflict of interest.

\section{References}

1. Gong, K.; Pan, Z.; Korayem, A.H.; Qiu, L.; Li, D.; Collins, F.; Wang, C.M.; Duan, W.H. Reinforcing effects of graphene oxide on portland cement paste. J. Mater. Civ. Eng. 2015, 27, A4014010. [CrossRef]

2. Li, N.; Jin, Z.; Long, G.; Chen, L.; Fu, Q.; Yu, Y.; Zhang, X.; Xiong, C. Impact resistance of steel fiber-reinforced self-compacting concrete (SCC) at high strain rates. J. Build. Eng. 2021, 38, 102212. [CrossRef]

3. Singh, N.K.; Rai, B. Assessment of synergetic effect on microscopic and mechanical properties of steel-polypropylene hybrid fiber reinforced concrete. Struct. Concr. 2021, 22, 516-534. [CrossRef]

4. Małek, M.; Jackowski, M.; Łasica, W.; Kadela, M.; Wachowski, M. Mechanical and material properties of mortar reinforced with glass fiber: An experimental study. Materials 2021, 14, 698. [CrossRef]

5. Wang, Z.; Ma, G.; Ma, Z.; Zhang, Y. Flexural behavior of carbon fiber-reinforced concrete beams under impact loading. Cem Concr Compos. 2021, 118, 103910. [CrossRef]

6. Park, T.; Her, S.; Jee, H.; Yoon, S.; Cho, B.; Hwang, S.-H.; Bae, S. Evaluation of orientation and distribution of steel fibers in highperformance concrete column determined via micro-computed tomography. Constr. Build. Mater. 2021, 270, 121473. [CrossRef]

7. Xue, G.; Yilmaz, E.; Song, W.; Cao, S. Fiber length effect on strength properties of polypropylene fiber reinforced cemented tailings backfill specimens with different sizes. Constr. Build. Mater. 2020, 241, 118113. [CrossRef]

8. Cao, S.; Zheng, D.; Yilmaz, E.; Yin, Z.; Xue, G.; Yang, F. Strength development and microstructure characteristics of artificial concrete pillar considering fiber type and content effects. Constr. Build. Mater. 2020, 256, 119408. [CrossRef]

9. Parveen, S.; Rana, S.; Fangueiro, R. A review on nanomaterial dispersion, microstructure, and mechanical properties of carbon nanotube and nanofiber reinforced cementitious composites. J. Nanomater. 2013, 2013, 710175. [CrossRef]

10. Liu, J.; Fu, J.; Ni, T.; Yang, Y. Fracture toughness improvement of multi-wall carbon nanotubes/graphene sheets reinforced cement paste. Constr. Build. Mater. 2019, 200, 530-538. [CrossRef]

11. Zhao, L.; Guo, X.; Song, L.; Song, Y.; Dai, G.; Liu, J. An intensive review on the role of graphene oxide in cement-based materials. Constr. Build. Mater. 2020, 241, 117939. [CrossRef]

12. Liew, K.; Kai, M.; Zhang, L. Carbon nanotube reinforced cementitious composites: An overview. Compos. Part A Appl. Sci. Manuf. 2016, 91, 301-323. [CrossRef]

13. Iijima, S.; Ichihashi, T. Single-shell carbon nanotubes of 1-nm diameter. Nature 1993, 363, 603-605. [CrossRef]

14. Siddique, R.; Mehta, A. Effect of carbon nanotubes on properties of cement mortars. Constr. Build. Mater. 2014, 50, 116129. [CrossRef]

15. Georgakilas, V.; Perman, J.A.; Tucek, J.; Zboril, R. Broad family of carbon nanoallotropes: Classification, chemistry, and applications of fullerenes, carbon dots, nanotubes, graphene, nanodiamonds, and combined superstructures. Chem. Rev. 2015, 115, 4744-4822. [CrossRef] [PubMed]

16. Yu, M.-F.; Lourie, O.; Dyer, M.J.; Moloni, K.; Kelly, T.F.; Ruoff, R.S. Strength and breaking mechanism of multiwalled carbon nanotubes under tensile load. Science 2000, 287, 637-640. [CrossRef]

17. Zhang, Q.; Huang, J.Q.; Qian, W.Z.; Zhang, Y.Y.; Wei, F. The road for nanomaterials industry: A review of carbon nanotube production, post-treatment, and bulk applications for composites and energy storage. Small 2013, 9, 1237-1265. [CrossRef]

18. Chaipanich, A.; Nochaiya, T.; Wongkeo, W.; Torkittikul, P. Compressive strength and microstructure of carbon nanotubes-fly ash cement composites. Mater. Sci. Eng. A 2010, 527, 1063-1067. [CrossRef]

19. Assi, L.; Alsalman, A.; Bianco, D.; Ziehl, P.; El-Khatib, J.; Bayat, M.; Hussein, F.H. Multiwall Carbon Nanotubes (MWCNTs) Dispersion \& Mechanical Effects in OPC Mortar \& Paste: A review. J. Build. Eng. 2021, 43, 102512. 
20. Neto, J.D.S.A.; Santos, T.A.; de Andrade Pinto, S.; Dias, C.M.R.; Ribeiro, D.V. Effect of the combined use of carbon nanotubes (CNT) and metakaolin on the properties of cementitious matrices. Constr. Build. Mater. 2021, 271, 121903. [CrossRef]

21. Li, Y.; Li, H.; Jin, C. Effect of multi-walled carbon nanotubes on the damping property of cement mortar and mechanism analysis. Arch. Civ. Mech. Eng. 2021, 21, 1-14. [CrossRef]

22. Xu, S.; Liu, J.; Li, Q. Mechanical properties and microstructure of multi-walled carbon nanotube-reinforced cement paste. Constr. Build. Mater. 2015, 76, 16-23. [CrossRef]

23. Kharisov, B.I.; Kharissova, O.V.; Méndez, U.O. Methods for dispersion of carbon nanotubes in water and common solvents. MRS Online Proc. Libr. 2014, 1700, 109-114. [CrossRef]

24. Dyke, C.A.; Tour, J.M. Covalent functionalization of single-walled carbon nanotubes for materials applications. J. Phys. Chem. A 2004, 108, 11151-11159. [CrossRef]

25. Jeon, I.-Y.; Chang, D.W.; Kumar, N.A.; Baek, J.-B. Functionalization of carbon nanotubes. In Carbon Nanotubes-Polymer Nanocomposites; IntechOpen: London, UK, 2011; pp. 91-110.

26. Mousavi, M.A.; Bahari, A. Influence of functionalized MWCNT on microstructure and mechanical properties of cement paste. Sādhanā 2019, 44, 103. [CrossRef]

27. Chen, J.; Yao, B.; Li, C.; Shi, G. An improved Hummers method for eco-friendly synthesis of graphene oxide. Carbon 2013, 64, 225-229. [CrossRef]

28. Gong, S.; Ni, H.; Jiang, L.; Cheng, Q. Learning from nature: Constructing high performance graphene-based nanocomposites. Mater. Today 2017, 20, 210-219. [CrossRef]

29. Zhu, Y.; Murali, S.; Cai, W.; Li, X.; Suk, J.W.; Potts, J.R.; Ruoff, R.S. Graphene and graphene oxide: Synthesis, properties, and applications. Adv. Mater. 2010, 22, 3906-3924. [CrossRef] [PubMed]

30. Peng, H.; Ge, Y.; Cai, C.; Zhang, Y.; Liu, Z. Mechanical properties and microstructure of graphene oxide cement-based composites. Constr. Build. Mater. 2019, 194, 102-109. [CrossRef]

31. Pan, Z.; He, L.; Qiu, L.; Korayem, A.H.; Li, G.; Zhu, J.W.; Collins, F.; Li, D.; Duan, W.H.; Wang, M.C. Mechanical properties and microstructure of a graphene oxide-cement composite. Cem. Concr. Compos. 2015, 58, 140-147. [CrossRef]

32. An, J.; McInnis, M.; Chung, W.; Nam, B.H. Feasibility of using graphene oxide nanoflake (GONF) as additive of cement composite. Appl. Sci. 2018, 8, 419. [CrossRef]

33. Liu, J.; Suh, H.; Jee, H.; Xu, J.; Nezhad, E.Z.; Choi, C.-S.; Bae, S. Synergistic effect of carbon nanotube/TiO 2 nanotube multi-scale reinforcement on the mechanical properties and hydration process of portland cement paste. Constr. Build. Mater. 2021, 293, 123447. [CrossRef]

34. Lu, Z.; Hou, D.; Meng, L.; Sun, G.; Lu, C.; Li, Z. Mechanism of cement paste reinforced by graphene oxide/carbon nanotubes composites with enhanced mechanical properties. RSC Adv. 2015, 5, 100598-100605. [CrossRef]

35. Zhou, C.; Li, F.; Hu, J.; Ren, M.; Wei, J.; Yu, Q. Enhanced mechanical properties of cement paste by hybrid graphene oxide/carbon nanotubes. Constr. Build. Mater. 2017, 134, 336-345. [CrossRef]

36. Kaur, R.; Kothiyal, N. Positive synergistic effect of superplasticizer stabilized graphene oxide and functionalized carbon nanotubes as a 3-D hybrid reinforcing phase on the mechanical properties and pore structure refinement of cement nanocomposites. Constr. Build. Mater. 2019, 222, 358-370. [CrossRef]

37. William, S.; Hummers, J.; Offeman, R.E. Preparation of graphitic oxide. J. Am. Chem. Soc. 1958, 80, 1339.

38. Eigler, S.; Hirsch, A. Chemistry with graphene and graphene oxide-challenges for synthetic chemists. Angew. Chem. Int. Ed. 2014, 53, 7720-7738. [CrossRef]

39. Yu, H.; Zhang, B.; Bulin, C.; Li, R.; Xing, R. High-efficient synthesis of graphene oxide based on improved hummers method. Sci. Rep. 2016, 6, 36143. [CrossRef]

40. Marcano, D.C.; Kosynkin, D.V.; Berlin, J.M.; Sinitskii, A.; Sun, Z.; Slesarev, A.; Alemany, L.B.; Lu, W.; Tour, J.M. Improved synthesis of graphene oxide. ACS Nano 2010, 4, 4806-4814. [CrossRef]

41. Datsyuk, V.; Kalyva, M.; Papagelis, K.; Parthenios, J.; Tasis, D.; Siokou, A.; Kallitsis, I.; Galiotis, C. Chemical oxidation of multiwalled carbon nanotubes. Carbon 2008, 46, 833-840. [CrossRef]

42. Al Mgheer, T.; Abdulrazzak, F.H. Oxidation of multi-walled carbon nanotubes in acidic and basic Piranha mixture. Front. Nanosci. Nanotechnol. 2016, 2, 155-158. [CrossRef]

43. Rahman, M.J.; Mieno, T. Water-dispersible multiwalled carbon nanotubes obtained from citric-acid-assisted oxygen plasma functionalization. J. Nanomater. 2014, 2014, 508192. [CrossRef]

44. Njuguna, J.; Vanli, O.A.; Liang, R. A review of spectral methods for dispersion characterization of carbon nanotubes in aqueous suspensions. J. Spectrosc. 2015, 2015, 463156. [CrossRef]

45. Rance, G.A.; Marsh, D.H.; Nicholas, R.J.; Khlobystov, A.N. UV-vis absorption spectroscopy of carbon nanotubes: Relationship between the $\pi$-electron plasmon and nanotube diameter. Chem. Phys. Lett. 2010, 493, 19-23. [CrossRef]

46. Elkashef, M.; Abou-Zeid, M.N. Performance of carbon nanotubes in mortar using different surfactants. Can. J. Civ. Eng. 2017, 44, 619-625. [CrossRef]

47. Sharma, S.; Kothiyal, N.; Chitkara, M. Enhanced mechanical performance of cement nanocomposite reinforced with graphene oxide synthesized from mechanically milled graphite and its comparison with carbon nanotubes reinforced nanocomposite. RSC Adv. 2016, 6, 103993-104009. [CrossRef] 
48. Kaur, R.; Kothiyal, N. Comparative effects of sterically stabilized functionalized carbon nanotubes and graphene oxide as reinforcing agent on physico-mechanical properties and electrical resistivity of cement nanocomposites. Constr. Build. Mater. 2019, 202, 121-138. [CrossRef]

49. Kaur, R.; Kothiyal, N.; Singh, J. Ultrasonic and superplasticizer assisted dispersion of hybrid carbon nanomaterials (FCNT and GO): Its effect on early stage hydration and physico-mechanical strength of cement mortar. J. Adhes. Sci. Technol. 2020, 34, 192-218. [CrossRef]

50. Petrunin, S.; Vaganov, V.; Sobolev, K. The effect of functionalized carbon nanotubes on the performance of cement composites. NANOCON 2013, 10, 16-18.

51. Sahebian, S.; Zebarjad, S.; Vahdati Khaki, J.; Lazzeri, A. A study on the dependence of structure of multi-walled carbon nanotubes on acid treatment. J. Nanostructure Chem. 2015, 5, 287-293. [CrossRef]

52. Sindu, B.; Sasmal, S. Properties of carbon nanotube reinforced cement composite synthesized using different types of surfactants. Constr. Build. Mater. 2017, 155, 389-399. [CrossRef]

53. Du, S.; Wu, J.; AlShareedah, O.; Shi, X. Nanotechnology in cement-based materials: A review of durability, modeling, and advanced characterization. Nanomaterials 2019, 9, 1213. [CrossRef]

54. Zhang, M.-H.; Sisomphon, K.; Ng, T.S.; Sun, D.J. Effect of superplasticizers on workability retention and initial setting time of cement pastes. Constr. Build. Mater. 2010, 24, 1700-1707. [CrossRef]

55. Chuah, S.; Li, W.; Chen, S.J.; Sanjayan, J.G.; Duan, W.H. Investigation on dispersion of graphene oxide in cement composite using different surfactant treatments. Constr. Build. Mater. 2018, 161, 519-527. [CrossRef]

56. Chen, S.J.; Qiu, C.Y.; Korayem, A.H.; Barati, M.R.; Duan, W.H. Agglomeration process of surfactant-dispersed carbon nanotubes in unstable dispersion: A two-stage agglomeration model and experimental evidence. Powder Technol. 2016, 301, 412-420. [CrossRef]

57. ASTM. Standard Test Method for Compressive Strength of Hydraulic Cement Mortars (Using 2-In. or [50 mm] Cube Specimens). Available online: https:/ / compass.astm.org/EDIT/html_annot.cgi?C109+20b (accessed on 21 June 2021).

58. Jee, H.; Park, J.; Zalnezhad, E.; Jeong, K.; Woo, S.M.; Seok, S.; Bae, S. Characterization of Titanium Nanotube Reinforced Cementitious Composites: Mechanical Properties, Microstructure, and Hydration. Materials 2019, 12, 1617. [CrossRef] [PubMed]

59. ASTM. Standard Test Method for Splitting Tensile Strength of Cylindrical Concrete Specimens. Available online: https://compass astm.org/EDIT/html_annot.cgi?C496+17 (accessed on 21 June 2021).

60. Sedaghat, A.; Zayed, A.; Sandberg, P. Measurement and prediction of heat of hydration of portland cement using isothermal conduction calorimetry. J. Test. Eval. 2013, 41, 943-950. [CrossRef]

61. Chung, D.D. Carbon Composites: Composites with Carbon Fibers, Nanofibers, and Nanotubes; Butterworth-Heinemann: Oxford, UK, 2016.

62. Avilés, F.; Ponce, A.; Cauich-Rodríguez, J.; Martínez, G. TEM examination of MWCNTs oxidized by mild experimental conditions. Fuller. Nanotub. Carbon Nanostructures 2012, 20, 49-55. [CrossRef]

63. Musso, S.; Tulliani, J.-M.; Ferro, G.; Tagliaferro, A. Influence of carbon nanotubes structure on the mechanical behavior of cement composites. Compos. Sci. Technol. 2009, 69, 1985-1990. [CrossRef]

64. Zhao, L.; Guo, X.; Ge, C.; Li, Q.; Guo, L.; Shu, X.; Liu, J. Investigation of the effectiveness of PC@GO on the reinforcement for cement composites. Constr. Build. Mater. 2016, 113, 470-478. [CrossRef]

65. Zheng, M.; Diner, B.A. Solution redox chemistry of carbon nanotubes. J. Am. Chem. Soc. 2004, 126, 15490-15494. [CrossRef]

66. Fathi, M.; Saghafi, M.; Mahboubi, F. Graphene oxide nanoribbons and their applications in supercapacitors. J. Ultrafine Grained Nanostructured Mater. 2014, 47, 71-76.

67. Zhang, Y.; Liu, Y.; Chen, L.; Hu, X.; Zhang, L.; Hu, L.; Chen, Y. One-dimensional graphene nanoribbons hybridized with carbon nanotubes as cathode and anode interfacial layers for high performance solar cells. RSC Adv. 2015, 5, 49614-49622. [CrossRef]

68. Wang, K.; Pang, J.; Li, L.; Zhou, S.; Li, Y.; Zhang, T. Synthesis of hydrophobic carbon nanotubes/reduced graphene oxide composite films by flash light irradiation. Front. Chem. Sci. Eng. 2018, 12, 376-382. [CrossRef]

69. Ţucureanu, V.; Matei, A.; Avram, A.M. FTIR spectroscopy for carbon family study. Crit. Rev. Anal. Chem. 2016, 46, 502520. [CrossRef]

70. Wong, C.H.A.; Pumera, M. Highly conductive graphene nanoribbons from the reduction of graphene oxide nanoribbons with lithium aluminium hydride. J. Mater. Chem. C 2014, 2, 856-863. [CrossRef]

71. Cui, H.; Yan, X.; Monasterio, M.; Xing, F. Effects of various surfactants on the dispersion of MWCNTs-OH in aqueous solution. Nanomaterials 2017, 7, 262. [CrossRef] [PubMed]

72. Osorio, A.; Silveira, I.; Bueno, V.; Bergmann, $\mathrm{C} . \mathrm{H}_{2} \mathrm{SO}_{4} / \mathrm{HNO}_{3} / \mathrm{HCl}$-Functionalization and its effect on dispersion of carbon nanotubes in aqueous media. Appl. Surf. Sci. 2008, 255, 2485-2489. [CrossRef]

73. Harun, S.W. Technology and Innovations. In Handbook of Graphene; John Wiley \& Sons: Hoboken, NJ, USA, 2019 ; Volume 8.

74. Rubel, R.I.; Ali, M.H.; Jafor, M.A.; Alam, M.M. Carbon nanotubes agglomeration in reinforced composites: A review. AIMS Mater. Sci. 2019, 6, 756-780. [CrossRef]

75. Li, D.; Müller, M.B.; Gilje, S.; Kaner, R.B.; Wallace, G.G. Processable aqueous dispersions of graphene nanosheets. Nat. Nanotechnol. 2008, 3, 101-105. [CrossRef] [PubMed]

76. Fan, X.; Peng, W.; Li, Y.; Li, X.; Wang, S.; Zhang, G.; Zhang, F. Deoxygenation of exfoliated graphite oxide under alkaline conditions: A green route to graphene preparation. Adv. Mater. 2008, 20, 4490-4493. [CrossRef] 
77. Korayem, A.; Tourani, N.; Zakertabrizi, M.; Sabziparvar, A.; Duan, W. A review of dispersion of nanoparticles in cementitious matrices: Nanoparticle geometry perspective. Constr. Build. Mater. 2017, 153, 346-357. [CrossRef]

78. Wang, X.; Dong, S.; Ashour, A.; Zhang, W.; Han, B. Effect and mechanisms of nanomaterials on interface between aggregates and cement mortars. Constr. Build. Mater. 2020, 240, 117942. [CrossRef]

79. Mahinroosta, M.; Allahverdi, A. A Scoping Review on Integrating Inorganic Nanomaterials into Cement Composites. Adv. Civ. Eng. Mater. 2019, 8, 526-553. [CrossRef]

80. Lv, S.; Ma, Y.; Qiu, C.; Sun, T.; Liu, J.; Zhou, Q. Effect of graphene oxide nanosheets of microstructure and mechanical properties of cement composites. Constr. Build. Mater. 2013, 49, 121-127. [CrossRef]

81. Li, G.Y.; Wang, P.M.; Zhao, X. Mechanical behavior and microstructure of cement composites incorporating surface-treated multi-walled carbon nanotubes. Carbon 2005, 43, 1239-1245. [CrossRef]

82. Han, B.; Yu, X.; Ou, J. Multifunctional and Smart Carbon Nanotube Reinforced Cement-Based Materials. In Nanotechnology in Civil Infrastructure: A Paradigm Shift; Gopalakrishnan, K., Birgisson, B., Taylor, P., Attoh-Okine, N.O., Eds.; Springer: Berlin/Heidelberg, Germany, 2011; pp. 1-47.

83. Makar, J.; Margeson, J.; Luh, J. Carbon nanotube/cement composites-early results and potential applications. In Proceedings of the 3rd International Conference on Construction Materials: Performance, Innovations and Structural Implications, Vancouver, BC, USA, 22-24 August 2005; pp. 1-10.

84. Zhao, L.; Hou, D.; Wang, P.; Guo, X.; Zhang, Y.; Liu, J.; Zhang, J. Experimental and molecular dynamics studies on the durability of sustainable cement-based composites: Reinforced by graphene. Constr. Build. Mater. 2020, 257, 119566. [CrossRef]

85. Makar, J. The effect of SWCNT and other nanomaterials on cement hydration and reinforcement. In Nanotechnology in Civil Infrastructure; Springer: Berlin/Heidelberg, Germany, 2011; pp. 103-130.

86. Bullard, J.W.; Jennings, H.M.; Livingston, R.A.; Nonat, A.; Scherer, G.W.; Schweitzer, J.S.; Scrivener, K.L.; Thomas, J.J. Mechanisms of cement hydration. Cem. Concr. Res. 2011, 41, 1208-1223. [CrossRef]

87. Bae, S.; Kanematsu, M.; Hernández-Cruz, D.; Moon, J.; Kilcoyne, D.; Monteiro, P.J.M. In Situ Soft X-ray Spectromicroscopy of Early Tricalcium Silicate Hydration. Materials 2016, 9, 976. [CrossRef]

88. Zhao, L.; Guo, X.; Liu, Y.; Ge, C.; Guo, L.; Shu, X.; Liu, J. Synergistic effects of silica nanoparticles/polycarboxylate superplasticizer modified graphene oxide on mechanical behavior and hydration process of cement composites. RSC Adv. 2017, 7, 1668816702. [CrossRef]

89. Jansen, D.; Neubauer, J.; Goetz-Neunhoeffer, F.; Haerzschel, R.; Hergeth, W.-D. Change in reaction kinetics of a Portland cement caused by a superplasticizer-Calculation of heat flow curves from XRD data. Cem. Concr. Res. 2012, 42, 327-332. [CrossRef]

90. Uchikawa, H.; Hanehara, S.; Sawaki, D. The role of steric repulsive force in the dispersion of cement particles in fresh paste prepared with organic admixture. Cem. Concr. Res. 1997, 27, 37-50. [CrossRef]

91. Cui, H.; Yang, S.; Memon, S.A. Development of carbon nanotube modified cement paste with microencapsulated phase-change material for structural-functional integrated application. Int. J. Mol. Sci. 2015, 16, 8027-8039. [CrossRef] [PubMed]

92. Snellings, R.; Salze, A.; Scrivener, K. Use of X-ray diffraction to quantify amorphous supplementary cementitious materials in anhydrous and hydrated blended cements. Cem. Concr. Res. 2014, 64, 89-98. [CrossRef]

93. Chuah, S.; Pan, Z.; Sanjayan, J.G.; Wang, C.M.; Duan, W.H. Nano reinforced cement and concrete composites and new perspective from graphene oxide. Constr. Build. Mater. 2014, 73, 113-124. [CrossRef]

94. Xie, S.; Cheng, Z.; Wan, L. Hydration And Microstructure Of Astm Type I Cement Paste. SECM 2019, 26, 215-220. [CrossRef]

95. Mohsen, A.; Aiad, I.; El-Hossiny, F.; Habib, A. Evaluating the Mechanical Properties of Admixed Blended Cement Pastes and Estimating its Kinetics of Hydration by Different Techniques. Egypt. J. Pet. 2020, 29, 171-186. [CrossRef]

96. Habib, A.; Aiad, I.; El-Hosiny, F.; Abd El-Aziz, A. Development of the fire resistance and mechanical characteristics of silica fume-blended cement pastes using some chemical admixtures. Constr. Build. Mater. 2018, 181, 163-174. [CrossRef]

97. Tafesse, M.; Kim, H.-K. The role of carbon nanotube on hydration kinetics and shrinkage of cement composite. Compos. B Eng. 2019, 169, 55-64. [CrossRef]

98. Suh, H.; Jee, H.; Kim, J.; Kitagaki, R.; Ohki, S.; Woo, S.; Jeong, K.; Bae, S. Influences of rehydration conditions on the mechanical and atomic structural recovery characteristics of Portland cement paste exposed to elevated temperatures. Constr. Build. Mater. 2020, 235, 117453. [CrossRef]

99. Jee, H.; Im, S.; Kanematsu, M.; Suzuki, H.; Morooka, S.; Taku, K.; Machida, A.; Bae, S. Determination of atomistic deformation of tricalcium silicate paste with high-volume fly ash. J. Am. Ceram. Soc. 2020, 103, 7188-7201. [CrossRef]

100. Bae, S.; Jee, H.; Suh, H.; Kanematsu, M.; Shiro, A.; Machida, A.; Watanuki, T.; Shobu, T.; Morooka, S.; Geng, G. Analysis of atomistic structural deformation characteristics of calcium silicate hydrate in 53-year-old tricalcium silicate paste using atomic pair distribution function. Constr. Build. Mater. 2020, 237, 117714. [CrossRef]

101. Bae, S.; Jee, H.; Kanematsu, M.; Shiro, A.; Machida, A.; Watanuki, T.; Shobu, T.; Suzuki, H. Pair distribution function analysis of nanostructural deformation of calcium silicate hydrate under compressive stress. J. Am. Ceram. Soc. 2018, 101, 408-418. [CrossRef]

102. Scrivener, K.; Snellings, R.; Lothenbach, B. A Practical Guide to Microstructural Analysis of Cementitious Materials; CRC Press: Boca Raton, FL, USA, 2018. 